\title{
Glyoxal processing by aerosol multiphase chemistry: towards a kinetic modeling framework of secondary organic aerosol formation in aqueous particles
}

\author{
B. Ervens ${ }^{1,2}$ and R. Volkamer ${ }^{1,3}$ \\ ${ }^{1}$ Cooperative Institute for Research in Environmental Sciences, University of Colorado, Boulder, Colorado, USA \\ ${ }^{2}$ Chemical Sciences Division, Earth System Research Laboratory, NOAA, Boulder, Colorado, USA \\ ${ }^{3}$ Department of Biochemistry and Chemistry, University of Colorado, Boulder, CO, USA
}

Received: 22 April 2010 - Published in Atmos. Chem. Phys. Discuss.: 11 May 2010

Revised: 2 August 2010 - Accepted: 19 August 2010 - Published: 2 September 2010

\begin{abstract}
This study presents a modeling framework based on laboratory data to describe the kinetics of glyoxal reactions that form secondary organic aerosol (SOA) in aqueous aerosol particles. Recent laboratory results on glyoxal reactions are reviewed and a consistent set of empirical reaction rate constants is derived that captures the kinetics of glyoxal hydration and subsequent reversible and irreversible reactions in aqueous inorganic and water-soluble organic aerosol seeds. Products of these processes include (a) oligomers, (b) nitrogen-containing products, (c) photochemical oxidation products with high molecular weight. These additional aqueous phase processes enhance the SOA formation rate in particles and yield two to three orders of magnitude more SOA than predicted based on reaction schemes for dilute aqueous phase (cloud) chemistry for the same conditions (liquid water content, particle size).

The application of the new module including detailed chemical processes in a box model demonstrates that both the time scale to reach aqueous phase equilibria and the choice of rate constants of irreversible reactions have a pronounced effect on the predicted atmospheric relevance of SOA formation from glyoxal. During day time, a photochemical (most likely radical-initiated) process is the major SOA formation pathway forming $\sim 5 \mu \mathrm{g} \mathrm{m}^{-3} \mathrm{SOA}$ over $12 \mathrm{~h}$ (assuming a constant glyoxal mixing ratio of $300 \mathrm{ppt}$ ). During night time, reactions of nitrogen-containing compounds (ammonium, amines, amino acids) contribute most to the predicted SOA mass; however, the absolute predicted SOA masses are
\end{abstract}

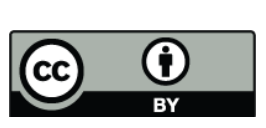

Correspondence to: B. Ervens

(barbara.ervens@noaa.gov)

R. Volkamer

(rainer.volkamer@colorado.edu) reduced by an order of magnitude as compared to day time production. The contribution of the ammonium reaction significantly increases in moderately acidic or neutral particles $(5<\mathrm{pH}<7)$.

Glyoxal uptake into ammonium sulfate seed under dark conditions can be represented with a single reaction parameter $k_{\text {effupt }}$ that does not depend on aerosol loading or water content, which indicates a possibly catalytic role of aerosol water in SOA formation. However, the reversible nature of uptake under dark conditions is not captured by $k_{\text {effupt }}$, and can be parameterized by an effective Henry's law constant including an equilibrium constant $K_{\text {olig }}=1000$ (in ammonium sulfate solution). Such reversible glyoxal oligomerization contributes $<1 \%$ to total predicted SOA masses at any time.

Sensitivity tests reveal five parameters that strongly affect the predicted SOA mass from glyoxal: (1) time scales to reach equilibrium states (as opposed to assuming instantaneous equilibrium), (2) particle $\mathrm{pH}$, (3) chemical composition of the bulk aerosol, (4) particle surface composition, and (5) particle liquid water content that is mostly determined by the amount and hygroscopicity of aerosol mass and to a lesser extent by the ambient relative humidity.

Glyoxal serves as an example molecule, and the conclusions about SOA formation in aqueous particles can serve for comparative studies of other molecules that form SOA as the result of multiphase chemical processing in aerosol water. This SOA source is currently underrepresented in atmospheric models; if included it is likely to bring SOA predictions (mass and $\mathrm{O} / \mathrm{C}$ ratio) into better agreement with field observations.

Published by Copernicus Publications on behalf of the European Geosciences Union. 


\section{Introduction}

The prediction of the growth of atmospheric organic aerosols (OA) represents a major challenge in current modeling efforts due to the high uncertainties in sources, properties, reaction pathways and product volatility distribution of organics. In particular, the formation of OA from reaction products of volatile precursors ("secondary organic aerosol", SOA) is insufficiently described in models and their amount is underestimated by factors of 2-100 (DeGouw et al., 2005; Volkamer et al., 2006; Bahreini et al., 2009; Kleinman et al., 2009). The reasons for this discrepancy could both be due to the incomplete knowledge of precursors or insufficient understanding of the processes that convert organic gas phase precursors into low-volatility products that contribute to SOA.

Traditional OA models describe SOA formation by condensation of low-volatility and/or absorption of semi-volatile oxidation products from anthropogenic and biogenic precursors into the organic condensed phase. In this framework, only the saturation vapor pressure of the product and the amount of the preexisting organic portion of the aerosol mass determine the partitioning of gas-phase products between the gas and particle phase (Pankow, 1994; Odum et al., 1996; Griffin et al., 1999; Seinfeld and Pankow, 2003). Recent studies suggest a larger pool of OA precursors follows this conceptual framework of SOA formation and previously "missing" precursors can account for a significant portion of the missing SOA source in polluted air OA and their precursor gases evolve by becoming more oxidized, less volatile and more hygroscopic (Jimenez et al., 2009; Ervens et al., 2010). However, the chemical pathways by which this aging occurs in the atmosphere has mostly been considered in terms of gas-phase reactions of radicals $\left(\mathrm{OH}, \mathrm{NO}_{3}\right)$ and ozone with vapors that contain five or more carbon atoms (Claeys et al., 2004; Martin-Reviejo and Wirtz, 2005; Ng et al., 2007). Such gas-phase oxidation reactions do not explain SOA contributions from very volatile compounds like acetylene $\left(C_{2}\right)$ (e.g., Volkamer et al., 2007, 2009) and/or the formation of large organic molecules such as oligomers, organosulfates, and organonitrogen species that have been identified in ambient particles and rain water (Altieri et al., 2006; Denkenberger et al., 2007; Gomez-Gonzalez et al., 2008).

In several studies, it has been shown that SOA formed from glyoxal exhibits significant light absorption at $300 \mathrm{~nm}<\lambda<400 \mathrm{~nm}$ and to a smaller extent also at higher wavelengths (Debus, 1858; Shapiro et al., 2009). In Mexico City, where glyoxal contributes significantly to SOA formation (Volkamer et al., 2007), light absorption from "brown carbon" (Gelencser, 2004) at UV wavelengths accounts for up to $40 \%$ of the heating rate of black carbon (Barnard et al., 2008). This heating is currently not accounted for in estimates of the aerosol direct effect by the Intergovernmental Panel of Climate Change (IPCC) (Solomon et al., 2007). Brown carbon also slows down photochemistry by reducing photon actinic fluxes near ground level at those wavelengths that are responsible for most radical production (Volkamer et al., 2010b). Finally, the lower single scattering albedo is a sensitive parameter for the quantitative interpretation of solar straylight satellite retrievals (Dix et al., 2008).

In the aqueous phase, unique chemical reactions occur due to the presence of ions and hydrated species (e.g., diols) that have different properties and reactivity than their counterparts in the gas phase. For example, chemical processes in cloud droplets are the main contributor to sulfate formation (Seinfeld and Pandis, 1998) and have also been shown to contribute to organic mass (e.g., oxalate) formation (Ervens et al., 2003a; Warneck, 2003; Ervens et al., 2004a, b; Carlton et al., 2007). Analyses of cloud water samples have shown that $10-100 \%$ of highly soluble organic compounds (Henry's law constant $>10^{4} \mathrm{Matm}^{-1}$ ) such as glyoxal, glycolaldehyde and methylglyoxal are partitioned to the water phase (Limbeck and Puxbaum, 2000; van Pinxteren et al., 2005). Notably, the partitioning of these species can be described reasonably well based on thermodynamic equilibrium, i.e., within a factor of 0.6-3 (van Pinxteren et al., 2005) by application of Henry's law.

In contrast, measurements of the partitioning of the same compounds (glyoxal, glycolaldehyde, methylglyoxal) between aqueous particles (relative humidity $(\mathrm{RH})<100 \%$ ) and the gas phase reveal unusually large shifts in the partitioning towards particles. At $\mathrm{RH} \sim 80 \%$ (liquid water content (LWC) $\sim 10 \mu \mathrm{g} \mathrm{m}^{-3}$ ), $\sim 30-90 \%$ of these semivolatile species were associated with the particle phase (Matsunaga et al., 2004, 2005; Bao et al., 2009). These deviations from predicted thermodynamic equilibrium are too large to be explained by OA activity coefficients, which are thought to modify effective vapor pressures by less than one order of magnitude (Bowman and Melton, 2004). It seems rather likely that the enhanced partitioning to the particle phase is caused by the formation of high molecular weight products (e.g., oligomers) which remain difficult to identify at the molecular level. A few models predict SOA formation due to partitioning of soluble organics (Griffin et al., 2005; Chen et al., 2007; Pun and Seigneur, 2007). However, the further chemical processing of organics that might explain the enhanced partitioning into the aqueous particles has not been systematically explored due to the lack of suitable reaction rate constants that describe chemical and/or physical processes in the concentrated aerosol aqueous phase as compared to cloud droplets.

Over the past few years, glyoxal has gained great attention as a possible SOA precursor in the aqueous phase as a proxy for other small, water-soluble oxidation products. A particular interest in glyoxal stems from the fact that its global distribution is constrained from observations by satellites (Wittrock et al., 2006; Vrekoussis et al., 2009). Based on these global distributions most glyoxal forms over land (108 Tg/yr; $30 \%$ from biogenic (largely isoprene); $14 \%$ from anthropogenic; $6 \%$ from pyrogenic, and $50 \%$ from unaccounted 
sources; Stavrakou et al., 2009). Recent direct measurements of glyoxal over the oceans (Sinreich et al., 2010; Volkamer et al., 2010a) lend credibility to an additional ocean source ( $\sim 20-40 \mathrm{Tg} / \mathrm{yr}$, Myriokefalitakis et al., 2008; M. Kanakidou, personal communication, 2010). Glyoxal is rapidly lost in the gas phase by OH-reactions, photolysis, and to a minor extent through dry and wet deposition; these processes cap the atmospheric lifetime of glyoxal at a few hours during the day (Volkamer et al., 2005; Sander et al., 2006).

In clouds and fog, SOA production from glyoxal processing is well established from both experimental studies (Karpel vel Leitner and Doré, 1997; Schweitzer et al., 1998; Altieri et al., 2006; Loeffler et al., 2006; Carlton et al., 2007) and modeling studies (Ervens et al., 2003a; Warneck, 2003; Ervens et al., 2004a; Lim et al., 2005; Sorooshian et al., 2006; Ervens et al., 2008), and forms between $5.5 \mathrm{Tg} / \mathrm{yr}$ (Fu et al., 2008) and $10 \mathrm{Tg} / \mathrm{yr}$ (Stavrakou et al., 2009) SOA on global scales. In contrast, SOA formation from glyoxal in aerosol particles is only recently becoming an increasingly active field of experimental research. Several recent laboratory studies have shown that glyoxal uptake into aqueous solutions of inorganic (e.g., ammonium (bi)sulfate) and organic solutes (e.g., fulvic acid, dicarboxylic acids, amines, amino acids) is much more efficient than into pure water (Kroll et al., 2005; Liggio et al., 2005a, b; Corrigan et al., 2008; De Haan et al., 2009a, b, c; Galloway et al., 2009; Ip et al., 2009; Noziere et al., 2009a; Shapiro et al., 2009; Volkamer et al., 2009). Product studies have shown the formation of oligomers and nitrogen-containing compounds. In very acidic particles $(\mathrm{pH} \sim 0)$, sulfate esters from glyoxal have been identified (Surratt et al., 2007). It has been suggested that these species are formed by oxidation reaction of the $\mathrm{SO}_{4}^{-}$radical and alkyl radicals (Noziere et al., 2010; Perri et al., 2010). Further, the formation of the glycolic acid sulfate has been observed under irradiated conditions on moderately acidic seeds (Galloway et al., 2009). Notably, the SOA formation rate is strongly accelerated in the presence of an $\mathrm{OH}$ radical source (Volkamer et al., 2009). Furthermore, experiments with increasing glyoxal aqueous phase concentrations (from $\mu \mathrm{M}$ to $\mathrm{mM}$ ) have demonstrated that there is indeed a transition from 'dilute aqueous phase chemistry' with relatively simple oxidation products to more complex chemical processes at higher reactant concentrations that form oxidized, high molecular weight products (Altieri et al., 2006; Carlton et al., 2007; Tan et al., 2009). Glyoxal oligomer formation might even contribute to particle nucleation or efficient growth of freshly nucleated particles (Wang et al., 2010).

Field evidence suggests that particle phase reactions could be responsible for $10-15 \%$ of the SOA formation in Mexico City (Volkamer et al., 2007). Early laboratory evidence for surface-controlled uptake of glyoxal to aerosols (Liggio et al., 2005a, b) resulted in global model estimates of the potential role of SOA formation in aqueous particles that varied by more than an order of magnitude $(0.95-10.4 \mathrm{Tg} / \mathrm{yr})$ (Fu et al.,

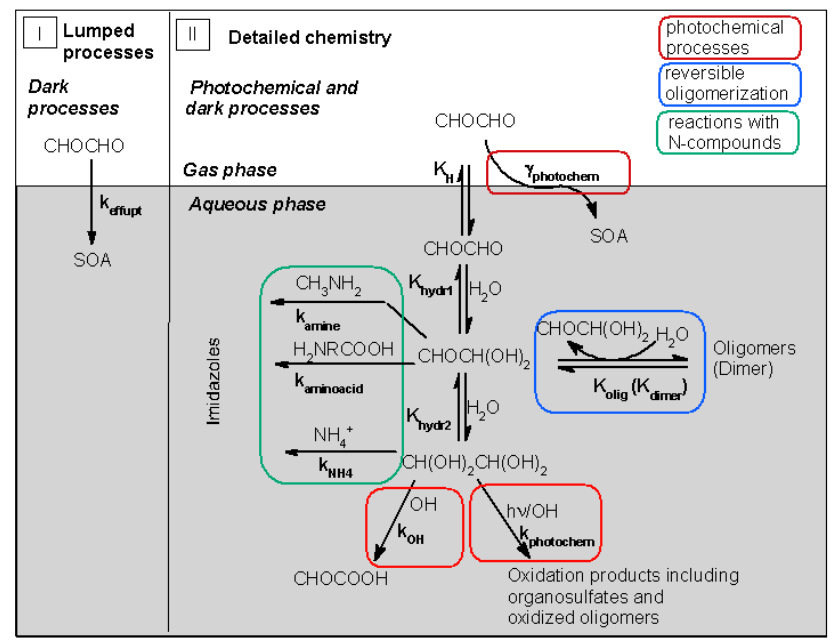

Fig. 1. Reaction scheme of glyoxal reactions in the aqueous phase based on literature and data derived in the present study. The terminology of the processes refers to the processes as included in Table 2 and in the text; all rate constants $k$ and equilibrium constants $K$ are defined in the Appendix. (I) $k_{\text {effupt }}$ refers to lumped parameterization of multiple dark processes (Sect. 3.1.); (II) shows all individual photochemical and dark processes discussed in Sects. 3.2 and 3.3.

2008, 2009; Stavrakou et al., 2009). However, other models did not quantify this glyoxal sink, recognizing the significant uncertainty in the physical and chemical understanding of the underlying processes (Myriokefalitakis et al., 2008).

While detailed chemical mechanisms for glyoxal formation and loss in the gas phase (Bloss et al., 2005) and in cloud droplets (Ervens et al., 2003a, 2004a) are available, SOA formation in aqueous particles has not been explored in detail with models due to the lack of suitable reaction parameters and mechanisms. The present study aims to close this gap by presenting (i) a theoretical description of chemical reactions in aqueous particles (Sect. 2); (ii) a comprehensive review of laboratory results, the discussion of their uncertainties and the derivation of a consistent set of reaction parameters (Sect. 3), (iii) the implementation of this newly developed aerosol module into an aerosol chemistry box model in order to explore the efficiency and sensitivities of glyoxal reactions in aerosol water for SOA formation under atmospherically relevant conditions (Sect. 4), and (iv) a discussion of gaps in the current framework and needs of future studies (Sect. 5).

\section{Framework of aqueous phase processes}

\subsection{Overview of processes}

The reaction scheme in Fig. 1 summarizes the chemical processes that have been proposed in the literature for glyoxal reactions in aqueous particles. On the left hand side, a 
simplified process (I) is shown that represents a lumped approach of glyoxal uptake under dark conditions and its subsequent particles phase reactions. The more detailed representation (II) includes individual chemical and physical processes that can be grouped into (1) reversible processes that lead to an equilibrium (uptake: $K_{\mathrm{H}}$, hydration: $K_{\text {hydr1 }}$, $K_{\text {hydr2 }}$, di-/oligomerisation $K_{\text {dimer }}, K_{\text {olig }}$ ), (2) irreversible processes that include (photochemical) oxidation, and others that form stable products ( $k_{\mathrm{OH}}, k_{\text {photochem }}, k_{\mathrm{NH}_{4}}, k_{\text {amine }}$, $\left.k_{\text {aminoacid }}\right)$, (3) heterogeneous processes that occur on the surface of particles $\left(\gamma_{\text {photochem }}\right)$. These processes, together with their representation in models, are discussed in the following sections. All rate constants $k$ and equilibrium constants $K$ with their corresponding indices are defined in the Appendix.

\subsection{Reversible processes: Henry's law and aqueous phase equilibria}

Reversible hydration reactions of aldehydes increase the solubility beyond the physical solubility $K_{\mathrm{H}}\left[\mathrm{M} \mathrm{atm}^{-1}\right]$ of pure aldehydes. In case of dialdehydes (e.g., glyoxal) the effective Henry's law constant due to hydration is expressed as

$K_{\mathrm{Heff}, \text { hydr }}=K_{\mathrm{H}}\left(1+K_{\mathrm{hydr} 1} \cdot K_{\mathrm{hydr} 2}\right)$

with $K_{\text {Heff,hydr }}=$ effective Henry's law constant (hydration) $\left[\mathrm{Matm}^{-1}\right]$ and dimensionless hydration equilibrium constants $K_{\text {hydr1 }}$ and $K_{\text {hydr2 }}$. These constants represent the ratio of hydration and dehydration rate constants $k_{\text {hydr }}\left[\mathrm{s}^{-1}\right]$ and $k_{\text {hydr }}^{\prime}\left[\mathrm{s}^{-1}\right]$ according to

$\mathrm{RCHO} \underset{k_{\text {hydr }}^{\prime}}{\stackrel{\left(+\mathrm{H}_{2} \mathrm{O}\right) k_{\text {hydr }}}{\rightleftharpoons}} \mathrm{RH}(\mathrm{OH})_{2} \quad K_{\text {hydr }}=k_{\text {hydr }} / k_{\text {hydr }}^{\prime}$

Here it is proposed that a similar approach can be applied to additional processes that shift the partitioning of glyoxal towards the aqueous phase due to the self reaction (dimer formation).

$K_{\mathrm{H}}{ }^{\text {dimer }}=K_{\mathrm{H}}\left(1+K_{\text {dimer }}\right)$

with $K_{\text {dimer }}=$ dimerization constant (dimensionless) describing the ratio of $k_{\text {dimer }}$ and $k_{\text {dimer }}^{\prime}$.

$$
\begin{aligned}
& \mathrm{RCH}(\mathrm{OH})_{2}+\mathrm{RCH}(\mathrm{OH})_{2} \underset{k_{\text {dimer }}^{\prime}}{\stackrel{k_{\text {dimer }}}{\rightleftharpoons}} \\
& \mathrm{R}-\mathrm{CH}(\mathrm{OH})-\mathrm{O}-\mathrm{CH}(\mathrm{OH})-\mathrm{R}+\mathrm{H}_{2} \mathrm{O}
\end{aligned}
$$

Dimerization of hydrated aldehydes (gem-diols) occurs by elimination of a water molecule resulting in a dimensionless $K_{\text {dimer }}$ with second-order rate constants $k_{\text {dimer }}$ and $k_{\text {dimer }}^{\prime}$ $\left[\mathrm{M}^{-1} \mathrm{~s}^{-1}\right]$ (Fig. 1). Further reaction steps similar to the dimerisation in Eq. (4) lead to oligomers, and the product of the additional equilibria can be lumped into a dimensionless

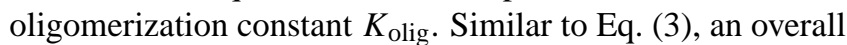
effective Henry's law constant $K_{\mathrm{H}}{ }^{*}\left[\mathrm{~mol} \mathrm{~kg}_{\mathrm{H}_{2} \mathrm{O}}{ }^{-1} \mathrm{~atm}^{-1}\right]$ is defined here that incorporates the uptake $\left(K_{\mathrm{H}}\right)$ and all further oligomerization equilibria:

$$
K_{\mathrm{H}}^{*}=K_{\mathrm{H}}\left(1+K_{\text {olig }}\right)
$$

Note that this terminology does not strictly follow the original definition of Henry's law that describes the partitioning between gas and solute phase in dilute ideal solutions: (i) including oligomeric products implies that the stoichiometry of the forward reaction of organic formation processes is more complex than a linear relationship between gas and aqueous phase concentrations as assumed by Henry's law. (ii) In the context of glyoxal uptake, many experiments have been performed in seed particles with highly concentrated inorganic (e.g., ammonium sulfate, ammonium bisulfate) and/or organic (e.g., fulvic acid) aqueous solutions. These solutions are not ideal and thus, deviate strongly from the conditions for which Henry's law is defined. (iii) While in many experimental studies, the partitioning of organic material is related to molar volumes (i.e. solute mass + water), in this study the approach by Volkamer et al. (2009) is adapted, and all $K_{\mathrm{H}}{ }^{*}$ are reported on a molal basis $\left[\mathrm{mol} \mathrm{kg}_{\mathrm{H}_{2} \mathrm{O}}{ }^{-1} \mathrm{~atm}^{-1}\right]$, i.e. related to water volume, not the total seed volume. While in dilute solutions, it is not necessary to distinguish between molal and molar concentrations as their difference is marginal, this is no longer true in concentrated aqueous aerosol particles. Despite these deviations from the original definition of Henry's law constants, throughout the present study $K_{\mathrm{H}}{ }^{*}$ is used in analogy to past studies but refers to molality.

\subsection{Multiphase processes: bulk reactions are rate- limiting}

The production and loss rates of soluble species in the aqueous phase are a combination of their phase transfer to/from the gas phase and their chemical production and loss $\left(P_{\mathrm{aq}}\right.$ and $L_{\mathrm{aq}}\left[\mathrm{M} \mathrm{s}^{-1}\right]$, respectively).

$\frac{d C_{\mathrm{aq}}}{d t}=k_{\mathrm{t}} \cdot\left(C_{\mathrm{g}}-\frac{C_{\mathrm{aq}}}{K_{\mathrm{H}}{ }^{(\mathrm{eff})} R T}\right)+P_{\mathrm{aq}}-L_{\mathrm{aq}}$

with concentrations in the aqueous $C_{\mathrm{aq}}[\mathrm{M}]$ and gas phase $C_{\mathrm{g}}$ [atm], respectively and the mass transfer coefficient $k_{\mathrm{t}}\left[\mathrm{s}^{-1}\right]$ that is a function of the drop radius $r$ [cm], gas phase diffusion coefficient $D_{\mathrm{g}}\left[\mathrm{cm}^{2} \mathrm{~s}^{-1}\right]$, mass accommodation coefficient $\alpha$ (dimensionless) and mean molecular velocity $\langle v\rangle$ $\left[\mathrm{cm} \mathrm{s}^{-1}\right]$ (Schwartz, 1986).

$k_{\mathrm{t}}=\left(\frac{r^{2}}{3 D_{\mathrm{g}}}+\frac{4 r}{3<v>\alpha}\right)^{-1}$

The phase transfer rate [atm s${ }^{-1}$ ] of gas phase species with the partial pressure $p$ [atm] to/from the aqueous phase depends on the amount of liquid water $w_{\mathrm{L}}\left[\mathrm{vol}_{\mathrm{aq}} / \mathrm{vol}_{\mathrm{g}}\right]$ and can be expressed as

$\frac{d p}{d t}=-w_{L} \cdot k_{t} \cdot\left(p-\frac{C_{\mathrm{aq}}}{K_{\mathrm{H}}{ }^{(\mathrm{eff})}}\right)+P_{\mathrm{g}}-L_{\mathrm{g}}$ 
Table 1. Summary of parameters that characterize the aqueous phase of cloud droplets and aqueous particles $(\mathrm{RH}<100 \%)$.

\begin{tabular}{lll}
\hline Parameter & Cloud droplets & Aqueous particles \\
\hline Liquid water content LWC $\left[\mathrm{g} \mathrm{m}^{-3}\right]$ & $\sim 0.1-1$ & $\sim 10^{-6}-10^{-5}$ \\
Diameter D $[\mu \mathrm{m}]$ & $\sim 1-50$ & $\sim 0.01-1$ \\
$\begin{array}{l}\text { Surface area of a particle (droplet) } \\
\mathrm{A}=\pi \mathrm{D}^{2}\left[\mathrm{~cm}^{2}\right]\end{array}$ & $\sim 10^{-6}$ & $\sim 10^{-10}$ \\
Number concentration $\mathrm{N}\left[\mathrm{cm}^{-3}\right]$ & $\sim 10-100$ & $100-10000$ \\
$\begin{array}{l}\text { Surface/Volume of a particle }(\text { droplet }) \\
\mathrm{A} /\left(\pi / 6 \mathrm{D}^{3}\right)\left[\mathrm{cm}^{-1}\right]\end{array}$ & $\sim 10^{4}$ & $\sim 10^{9}$ \\
$\begin{array}{l}\text { Surface/Volume of an aerosol particle } \\
\text { population A } /\left(\pi / 6 \mathrm{D}^{3}\right) \cdot \mathrm{N}\left[\mathrm{cm}^{-1} \mathrm{~cm}^{-3}\right]\end{array}$ & $\sim 10^{5}-10^{6}$ & $\sim 10^{11}-10^{13}$ \\
Lifetime & $\sim \min$ & $\sim$ days \\
\hline
\end{tabular}

where $P_{\mathrm{g}}$ and $L_{\mathrm{g}}$ are the chemical production and loss in the gas phase (Seinfeld and Pandis, 1998).

\subsection{Reactive uptake: surface processes are rate-limiting}

Heterogeneous processes that occur at the surface of droplets are often parameterized using a dimensionless reactive uptake coefficient $\gamma$ that describes the probability that a gas phase molecule reacts with a dissolved species at the gas/aqueous interface. The first-order loss $\left[\mathrm{s}^{-1}\right]$ of gas phase species with the concentration $C_{\mathrm{g}}\left[\mathrm{cm}^{-3}\right]$ can be described by

$\frac{d C_{\mathrm{g}}}{d t}=\frac{1}{4} \cdot \gamma \cdot A<v>\cdot C_{\mathrm{g}}$

with $A=$ total surface area $\left[\mathrm{cm}^{2}\right]$. The production of aqueous phase products can be directly equated to the loss of gas phase species. The parameter $\gamma$ is usually smaller than the mass accommodation coefficient $\alpha$ (Eq. 7) since the latter only accounts for the "sticking probability" on the surface but not the subsequent reaction probability.

\subsection{Differences of the aqueous phase of deliquesced particles and cloud droplets}

While the processes as described in the previous section can occur in or on any aqueous phase in the atmosphere, differences in the abolsute rates can be expected for dilute cloud droplets and aqueous particles. The aqueous phase of cloud droplets and deliquesced particles differ significantly in terms of parameters that impact reaction rates of multiphase and/or heterogeneous processes (Table 1): deliquesced particles usually exhibit mean diameters of up to a few hundreds of nm while cloud droplets can grow into sizes of several tens of $\mu \mathrm{m}$ with total LWCs $\left[\mathrm{g} \mathrm{m}^{-3}\right.$ ] that differ by about five orders of magnitude as compared to deliquesced particles. The interplay of bulk and surface processes in and on aqueous phases depends on the surface/volume ratio of the aerosol population $\left[\mathrm{cm}^{2} \mathrm{~cm}^{-3}\right]$ that is larger by $\sim 10^{6}-$ $10^{7}$ for particles. The concentrations of dissolved particle constituents (e.g., sulfate or water-soluble organics) scale inversely with the volume of the particles and droplets, resulting in typical concentrations of $\sim \mathrm{M}$ and $\sim \mu \mathrm{M}$ in particles and clouds, respectively.

At subsaturated conditions $(\mathrm{RH}<100 \%)$ particles usually reach their equilibrium sizes and LWC is mostly determined by the amount of hygroscopic material and ambient $\mathrm{RH}$. The formation and growth of cloud droplets depends on the supersaturation that, in turn, is a function of the cooling rate and water vapor condensation onto particles. These dynamic feedbacks determine the lifetime ( $\sim$ several minutes $)$ and sizes of cloud droplets.

\section{Assessment of literature data}

\subsection{Surface vs. bulk limitation in the kinetics of glyoxal uptake}

The approach shown in Eq. (9) has been used to interpret the uptake of glyoxal onto aqueous particles under dark conditions. With all other parameters known, the reactive uptake parameter $\gamma$ had been fit to measured glyoxal losses in two experimental studies (Hastings et al., 2005; Liggio et al., $2005 \mathrm{a}, \mathrm{b})$ and is in agreement with uptake studies of other carbonyl compounds on various surfaces. The two values for $\gamma$ derived from these studies differ by several orders of magnitude $\left(\gamma \sim 10^{-7}\right.$, Hastings et al. (2005); $\gamma=2.9 \times 10^{-3}$, Liggio et al., 2005a). It has been speculated that the lower $\gamma$ might have been caused by kinetic limitations due to very high glyoxal concentrations and accumulation of glyoxal at the particle surface (Hastings et al., 2005).

As an alternative approach to the surface-controlled uptake, in the following the results of the aforementioned studies are interpreted as a direct uptake of glyoxal into the particle phase. Comparing the increase in SOA mass (volume) in these experiments one can express the SOA formation rate as

$\frac{d[\mathrm{SOA}]}{d t}=k_{\text {effupt }}[\mathrm{SOA}]$

The overall rate constant $k_{\text {effupt }}$ represents a parameter that combines uptake processes and subsequent particle phase process(es). Since it can be assumed that the glyoxal loss is proportional to the increase of SOA mass, Eq. (10a) can be rewritten as

$\frac{d[\mathrm{Gly}]_{\mathrm{gas}}}{d t}=-k_{\mathrm{effupt}}[\text { Glyoxal }]_{\mathrm{gas}}$

This process is shown on the left hand side (I) of Fig. 1 and is contrasted with the more detailed 
Table 2. Summary of reaction parameters of glyoxal reactions in the aqueous phase that are reported in the literature or have been derived in the present study based on laboratory studies. All rate constants $k$ and equilibrium constants $K$ are defined in the Appendix.

\begin{tabular}{|c|c|c|c|c|}
\hline & Reaction & $\begin{array}{l}\text { Equilibrium } \\
\text { constant }\end{array}$ & $\begin{array}{l}\text { Rate constants } \\
\text { forward/back reaction } k, k^{\prime}\end{array}$ & Comment \\
\hline uptake & $\operatorname{Glyoxal}(\mathrm{g}) \leftrightarrow \operatorname{Glyoxal}(\mathrm{aq})$ & $\begin{array}{l}K_{\mathrm{H}, \mathrm{Hydr}}=3 \times 10^{5} \mathrm{M} \mathrm{atm}^{-1} \\
K_{\mathrm{H}, \mathrm{Hydr}}=4.19 \times 10^{5} \mathrm{M} \mathrm{atm}^{-1} \\
K_{\mathrm{H}, \mathrm{Hydr}}=3.6 \times 10^{5} \mathrm{M} \mathrm{atm}^{-1} \\
\alpha=0.023 ; D_{\mathrm{g}}=1.15 \mathrm{~cm}^{2} \mathrm{~s}^{-1}\end{array}$ & & $\begin{array}{l}\text { Betterton and Hoffmann, } 1988 \\
\text { Ip et al., 2009 } \\
\text { Zhou and Mopper, } 1990 \\
\text { Ervens et al., 2003a }\end{array}$ \\
\hline \multirow[t]{2}{*}{ (R1a) } & $\begin{array}{l}(\mathrm{CHO})_{2}+\mathrm{H}_{2} \mathrm{O} \leftrightarrow \\
\mathrm{CHOCH}(\mathrm{OH})_{2}\end{array}$ & $K_{\text {hydr } 1}=350^{\circ}$ & $k_{\text {hydr1 }}=7 \mathrm{~s}^{-1} ; k_{\text {hydr1 }}^{\prime}=0.02 \mathrm{~s}^{-1}$ & $k_{\text {hydr1: }}^{\prime}$ Wasa and Musha, 1970 \\
\hline & & & $k_{\text {hydr1 }}=11 \mathrm{~s}^{-1} ; h_{\text {hydr1 }}^{\prime}=0.03 \mathrm{~s}^{-1}$ & $\begin{array}{l}k_{\text {hydr1 }}=k_{\text {hydr1 }}(\text { methylglyoxal }) \\
\text { Creighton et al., } 1988\end{array}$ \\
\hline (R1b) & $\begin{array}{l}\mathrm{CHOCH}(\mathrm{OH})_{2}+\mathrm{H}_{2} \mathrm{O} \leftrightarrow \\
\left(\mathrm{CH}(\mathrm{OH})_{2}\right)_{2}\end{array}$ & $K_{\text {hydr2 }}=207$ & $\begin{array}{l}k_{\mathrm{hydr} 2}=4 \mathrm{~s}^{-1} ; k_{\mathrm{hydr} 2}^{\prime}=0.02 \mathrm{~s}^{-1} \\
k_{\mathrm{hydr} 2}=6.5 \mathrm{~s}^{-1} ; k_{\mathrm{hydr} 2}^{\prime}=0.03 \mathrm{~s}^{-1}\end{array}$ & $\begin{array}{l}\text { assuming lifetime of hydrates to be } \\
\text { the same for both hydrates } \\
\text { assuming lifetime of hydrates to be } \\
\text { the same for both hydrates }\end{array}$ \\
\hline (R2) & Gly + Gly (a) & $K_{\text {dimer }}=0.56 \mathrm{M}^{-1}$ & $\begin{array}{l}k_{\text {dimer }} \sim 10^{-4} \mathrm{M}^{-1} \mathrm{~s}^{-1} \\
k_{\text {dimer }}^{\prime} \sim 1.8 \times 10^{-4} \mathrm{~s}^{-1}(\mathrm{pH}=2)^{(\mathrm{b})} \\
k_{\text {dimer }} \sim 10^{-3} \mathrm{M}^{-1} \mathrm{~s}^{-1} ; \\
k_{\text {dimer }}^{\prime} \sim 1.8 \times 10^{-3}(\mathrm{pH}=5)^{(\mathrm{b})} \\
k_{\text {dimer }} \sim 10^{-2} \mathrm{M}^{-1} \mathrm{~s}^{-1} ; \\
k_{\text {dimer }}^{\prime} \sim 1.8 \times 10^{-2} \mathrm{~s}^{-1}(\mathrm{pH}=7)^{(\mathrm{b})}\end{array}$ & Fratzke and Reilly, 1986 \\
\hline (R3) & $\begin{array}{l}\mathrm{Gly}+\mathrm{CHOCH}(\mathrm{OH})_{2} \leftrightarrow \\
\text { oligomers }+\mathrm{H}_{2} \mathrm{O}\end{array}$ & $K_{\text {olig }}=1000$ & $k_{\text {olig }}=100 \mathrm{M}^{-1} \mathrm{~s}^{-1} ; k_{\text {olig }}^{\prime}=0.1 \mathrm{M}^{-1} \mathrm{~s}^{-1}$ & $\begin{array}{l}\text { this work, based on experiments } \\
\text { by Volkamer et al. (2009) }\end{array}$ \\
\hline (R4a) & Glyoxal (gas) $\rightarrow$ SOA & - & $k_{\text {effupt }}=5 \times 10^{-4} \mathrm{~s}^{-1}$ & $\begin{array}{l}\text { this work, based on experiments } \\
\text { by Volkamer et al. (2009) }\end{array}$ \\
\hline (R4b) & & - & $k_{\text {effupt }}=1.3 \times 10^{-4} \mathrm{~s}^{-1}$ & $\begin{array}{l}\text { this work, based on experiments } \\
\text { by Hastings et al. (2005) }\end{array}$ \\
\hline (R4c) & & - & $k_{\text {effupt }}=3.7 \times 10^{-4} \mathrm{~s}^{-1}$ & $\begin{array}{l}\text { this work, based on experiments } \\
\text { by Liggio et al. }(2005 \mathrm{a}, \mathrm{b})\end{array}$ \\
\hline (R5) & $\mathrm{Gly}+\mathrm{OH}$ & - & $k_{\mathrm{OH}}=10^{9} \mathrm{M}^{-1} \mathrm{~s}^{-1}$ & Ervens et al., 2003b \\
\hline (R6) & $\begin{array}{l}\mathrm{Gly}+h v / \mathrm{OH} \rightarrow \\
\text { oxidized oligomers }\end{array}$ & - & $\begin{array}{l}1.5 \mathrm{~s}^{-1}<k_{\text {photochem }}<18 \mathrm{~s}^{-1} \text { (non-hygrosc SOA) } \\
0.8 \mathrm{~s}^{-1}<k_{\text {photochem }}<7 \mathrm{~s}^{-1} \text { (hygrosc SOA) }\end{array}$ & $\begin{array}{l}\text { this work, } \\
\text { depending on seed composition (Fig. 3), } \\
\text { based on experiments by } \\
\text { Volkamer et al., } 2009\end{array}$ \\
\hline (R7) & Gly $\rightarrow$ SOA & & $\begin{array}{l}0.01<\gamma_{\text {photochem }}<0.03 \text { (non-hygrosc. SOA) } \\
0.005<\gamma_{\text {photochem }}<0.012 \text { (hygrosc. SOA) }\end{array}$ & $\begin{array}{l}\text { This work; upper limit } \\
\text { for surface processes derived on } \\
\text { ammonium sulfate/fulvic acid particles }\end{array}$ \\
\hline (R8) & $\mathrm{Gly}+\mathrm{NH}_{4}{ }^{+} \rightarrow$ Products & - & $\begin{array}{l}k_{\mathrm{NH} 4}=1.3 \times 10^{-7} \mathrm{M}^{-1} \mathrm{~s}^{-1}(\mathrm{pH}=2)^{(\mathrm{c})} \\
k_{\mathrm{NH} 4}=2.4 \times 10^{-4} \mathrm{M}^{-1} \mathrm{~s}^{-1}(\mathrm{pH}=5)^{(\mathrm{c})} \\
k_{\mathrm{NH} 4}=0.43 \mathrm{M}^{-1} \mathrm{~s}^{-1}(\mathrm{pH}=7)^{(\mathrm{c})}\end{array}$ & Noziere et al., 2009a \\
\hline (R9) & $\begin{array}{l}\mathrm{CHOCH}(\mathrm{OH})_{2}+\text { glycine } \rightarrow \\
\text { Products }(\mathrm{d}) \\
\mathrm{CHOCH}(\mathrm{OH})_{2}+\text { serine } \rightarrow \\
\text { Products }(\mathrm{d}) \\
\mathrm{CHOCH}(\mathrm{OH})_{2}+\text { arginine } \rightarrow \\
\text { Products }\end{array}$ & - & $\begin{array}{l}k_{\text {aminoacid }}=0.12 \mathrm{M}^{-1} \mathrm{~s}^{-1} \\
k_{\text {aminoacid }}=0.09 \mathrm{M}^{-1} \mathrm{~s}^{-1} \\
k_{\text {aminoacid }}=4.5 \times 10^{-4} \mathrm{M}^{-1} \mathrm{~s}^{-1}\end{array}$ & De Haan et al., 2009a \\
\hline (R10) & $\mathrm{CHOCH}(\mathrm{OH})_{2}+\mathrm{CH}_{3} \mathrm{NH}_{2}$ & - & $k_{\text {amine }}=(0.3 \pm 0.1) \mathrm{M}^{-1} \mathrm{~s}^{-1}$ & $\begin{array}{l}\text { D. De Haan, } \\
\text { personal communication, } 2009\end{array}$ \\
\hline
\end{tabular}

(a) Gly denotes the sum of unhydrated glyoxal, monohydrate and dihydrate;

(b) the data for $k_{\text {dimer }}$ are those reported in the original literature; $k_{\text {dimer }}^{\prime}$ are calculated based on $K_{\text {dimer }}$ (Eqs. 11-13). Note that in the expression as applied in the current study according to (R3), all $k_{\text {dimer }}$ should be multiplied with 207 ( $\left.K_{\text {hydr2 }}\right)$, cf. text;

(c) assuming an ammonium activity $a_{\mathrm{NH} 4}=1 \mathrm{M}$;

(d) these reactions only occur with the unprotonated form of the amino acids, $\left(p K_{\mathrm{a} 1}\right.$ (glycine) $=2.35 ; p K_{\mathrm{a} 2}(\mathrm{glycine})=9.78 ; p K_{\mathrm{a} 1}(\mathrm{serine})=2.19 ; p K_{\mathrm{a} 2}(\mathrm{serine})=9.21(\mathrm{Lide}, 2009)$.

mechanism (II) as discussed in the following sections. Notably, fitting the observed glyoxal loss rates or observed SOA mass formation rates (Hastings et al., 2005; Liggio et al., 2005a; Volkamer et al., 2009) leads to a narrow range of $1.3 \times 10^{-4} \mathrm{~s}^{-1}<k_{\text {effupt }}<5 \times 10^{-4} \mathrm{~s}^{-1}$ (Table 2) despite very different glyoxal concentrations $\left(\sim 1 \mathrm{ppb}<(\mathrm{CHO})_{2}(\mathrm{~g})<\sim 100 \mathrm{ppm}\right)$, and aerosol size distributions and loading $\left(\sim 0.7 \mu \mathrm{m}^{3} \mathrm{~cm}^{-3}-\sim 20 \mu \mathrm{m}^{3} \mathrm{~cm}^{-3}\right)$. This suggests that the surface area of the aerosol popula- tion does not control the uptake of glyoxal and its conversion into SOA mass. The excellent agreement of the derived $k_{\text {effupt }}$ suggests a catalytic mechanism in the presence of ammonium sulfate seed since the amount of seed mass (or water) does not affect the derived rate constant $k_{\text {effupt }}$. Since all experiments have been performed under dark conditions, and on seed aerosol of similar composition, the general application to any other seed cannot be evaluated. This approach does not require the knowledge of rate 
constants of individual processes or reactive uptake coefficients. It gives neither any information on the nature of the kinetically-limiting step for organic mass formation (phase transfer or subsequent particle phase reactions) nor on the underlying chemical mechanisms, reactants and products. In addition, $k_{\text {effupt }}$ only numerically describes glyoxal uptake and oligomer formation and thus implies an irreversible process. As it will be shown in Sect. 3.2, this assumption might lead to an overestimate of the net SOA production from dark oligomerization reactions, since it has been experimentally observed that these processes are reversible.

However, this approach is a very compact and simplified representation of glyoxal uptake and subsequent SOA formation in aqueous particles whose applicability needs to be evaluated for a wider range of experimental conditions (aerosol loading, composition, water content, importance of reversible character ("back reaction") etc).

The apparent absence of a surface process suggests that the application of Eq. (9) in model studies to evaluate SOA formation in aqueous solution as it has been done recently (Fu et al., 2008, 2009; Stavrakou et al., 2009) might be misleading. However, it will be shown in Sect. 3.3.1 that - depending on the solutes present in the aqueous particles - the description of glyoxal uptake as a pure bulk process might not be correct either under all conditions and a more complex interplay between bulk and surface processes can occur.

\subsection{Reversible glyoxal uptake}

\subsubsection{Henry's law constants and hydration}

Three measurements of the effective solubility ( $\left.K_{\text {Heff,hydr }}\right)$ of glyoxal are available in the literature (Betterton and Hoffmann, 1988; Zhou and Mopper, 1990; Ip et al., 2009) (Table 2). The lower limit $K_{\text {Heff, hydr }}=3 \times 10^{5} \mathrm{M} \mathrm{atm}^{-1}$ (Betterton and Hoffmann, 1988) is in good agreement with the more recent study that reports $K_{\mathrm{H}}=4.19 \times 10^{5} \cdot \exp \left[\left(62.2 \times 10^{3} / \mathrm{R}\right)\right.$. $(1 / T-1 / 298)] \mathrm{M} \mathrm{atm}^{-1}$ in pure water (Ip et al., 2009). The value in sea water $K_{\text {Heff,hydr }}=3.6 \cdot 10^{5} \mathrm{M} \mathrm{atm}^{-1}$ is very similar to the values in pure water, in agreement with trends for other small aldehydes that show only minor differences in $K_{\text {Heff,hydr }}$ in fresh and sea water (Zhou and Mopper, 1990). The hydration constants that are included in $K_{\mathrm{Heff}, \text { hydr }}$ (Eq. 1 ) are $K_{\text {hydr1 }}=207$ and $K_{\text {hydr2 }}=350$ (Ruiz-Montoya and Rodriguez-Mellado, 1994, 1995). These values, together with the constant given by Betterton and Hoffmann (1988), have been used to determine the physical solubility of glyoxal $K_{\mathrm{H}}=5 \mathrm{M} \mathrm{atm}^{-1}$ (Eq. 1) (Schweitzer et al., 1998). However, the $K_{\text {Heff,hydr }}$ value measured by Ip et al. (2009) might be more appropriate for pure water systems and results in a higher value, $K_{\mathrm{H}}=5.8 \mathrm{M} \mathrm{atm}^{-1}$ that is used in the current study.
In several recent studies, it has been shown that the unhydrated aldehyde group is more reactive towards various reactants (e.g., amino compounds) than an alcohol group in the gem-diol (Barsanti and Pankow, 2005; De Haan et al., 2009a, c). In order to correctly describe such processes in a multiphase system, the monohydrate fraction of glyoxal has to be known at any given time. To date, there is no direct measurement of the hydration kinetics of glyoxal available. However, there appears to be enough information to estimate the rate constants for hydration and dehydration of glyoxal (Eq. 2): Based on polarographic studies, the decay of the monohydrate under neutral conditions has been determined as $k_{\text {hydr1 }}^{\prime}=0.02 \mathrm{~s}^{-1}$ (Wasa and Musha, 1970). This yields a formation constant of $k_{\text {hydr1 }}\left(=K_{\mathrm{hydr} 1} \cdot k_{\mathrm{hydr} 1}^{\prime}\right)=7 \mathrm{~s}^{-1}$, in good agreement with the hydration constant for methylglyoxal $\left(k_{\text {hydr }}=11 \mathrm{~s}^{-1}\right.$, (Creighton et al., 1988)). Assuming that the resulting lifetime for the monohydrate is the same for the dihydrate, values for $k_{\mathrm{hydr} 2}=4 \mathrm{~s}^{-1}$ and $k_{\mathrm{hydr} 2}^{\prime}=0.02 \mathrm{~s}^{-1}$ can be determined (Table 2).

\subsubsection{Dimer formation of glyoxal}

Glyoxal concentrations in the atmospheric dilute aqueous phase (cloud/fog droplets) are in the range of $\mu \mathrm{M}$ (Igawa et al., 1989). If aqueous glyoxal concentrations exceed $\sim 1 \mathrm{M}$ dimerization becomes likely (Fratzke and Reilly, 1986) ( $K_{\text {dimer }}$, Fig. 1$)$. In a computational study, it has been shown that the dioxolane ring (dimer monohydrate) is the thermodynamically and kinetically most favored structure (Kua et al., 2008). Thermodynamical calculations suggest that with increasing glyoxal amounts at a given water mass (= high glyoxal/water mass ratios) not only dimers but also trimers (and their hydrates) will be abundant and contribute to organic mass (Barsanti and Pankow, 2005). Whereas the equilibrium constant of the dimerization $K_{\text {dimer }}$ is not $\mathrm{pH}$ dependent, the rate constant of the dimer decay $\left(k_{\text {dimer }}^{\prime}\right)$ shows a strong pH dependence (Reaction R2, Table 2) (Fratzke and Reilly, 1986). In this latter study, the dimerization rates $R_{\text {dimer }}$ have been derived assuming that any two forms of glyoxal [Gly total , i.e., unhydrated and hydrated (mono-, dihydrate), can react to form a dimer:

$R_{\text {dimer }}=\left[\mathrm{Gly}_{\text {total }}\right]^{2} \cdot k_{\text {dimer,total }}$

with rate constants $1.7 \times 10^{-5} \mathrm{M}^{-1} \mathrm{~s}^{-1}$

$<\mathrm{k}_{\text {dimer,total }}<5.6 \times 10^{-3} \mathrm{M}^{-1} \mathrm{~s}^{-1}$

$(3<\mathrm{pH}<7)$. However, recognizing that theoretical studies suggest that the monohydrate is the most reactive species (Barsanti and Pankow, 2005; Kua et al., 2008), the rate constants by Fratzke and Reilly are expressed in the present study as a combination of the monohydrate concentration $\left[\left(\mathrm{CHOC}(\mathrm{OH})_{2}\right)\right]$, and [Gly total $]$

$R_{\text {dimer }}=\left[\mathrm{CHOC}(\mathrm{OH})_{2}\right]\left[\mathrm{Gly}_{\text {total }}\right] \cdot k_{\text {dimer }}$ 
Table 3. Effective Henry's law constants derived in experimental studies. Note that all constants are converted to a molal basis $\left[\mathrm{mol} \mathrm{kg}_{\mathrm{H}_{2} \mathrm{O}}{ }^{-1} \mathrm{~atm}^{-1}\right]$ and, thus, differ from the constants in the original literature. The dimensionless oligomerization constant $K_{\mathrm{olig}}$ has been derived based on Eq. (5) (Sect. 2.2).

\begin{tabular}{lllll}
\hline Solute & $K_{\mathrm{H}}{ }^{*}\left[\mathrm{~mol} \mathrm{~kg} \mathrm{H}_{2} \mathrm{O}^{-1} \mathrm{~atm}^{-1}\right]$ & Solute molarity [M] & Reference $\mathrm{K}_{\mathrm{H}}{ }^{*}$ & $K_{\text {olig }}$ \\
\hline$\left(\mathrm{NH}_{4}\right)_{2} \mathrm{SO}_{4}$ & $(1.5 \pm 0.4) \times 10^{8}$ & $1.8-2.1$ & Galloway et al., 2009 & 1500 \\
$\left(\mathrm{NH}_{4}\right)_{2} \mathrm{SO}_{4}$ & $(1.0 \pm 0.2) \times 10^{8}$ & $2.4-7.6$ & Kroll et al., 2005 & 1000 \\
$\left(\mathrm{NH}_{4}\right)_{2} \mathrm{SO}_{4} / \mathrm{H}_{2} \mathrm{SO}_{4}$ & $(7.7 \pm 4.2) \times 10^{7}$ & $1.2-3.2$ & Kroll et al., 2005 & 770 \\
$\mathrm{NaCl}$ & $1.9 \times 10^{6}$ & 0.05 & Ip et al., 2009 & 4.5 \\
& $1.1 \times 10^{6}$ & 4 & & 2.6 \\
$\mathrm{Na}_{2} \mathrm{SO}_{4}$ & $2.4 \times 10^{7}$ & 0.01 & Ip et al., 2009 & 57 \\
$\mathrm{Na}_{2} \mathrm{SO}_{4}$ & $>3 \times 10^{8}$ & 5 & Corrigan et al., 2008 & 720 \\
\hline
\end{tabular}

Since the monohydrate concentration contributes only $\sim 0.5 \%\left(K_{\text {hydr1 }}{ }^{-1}=1 / 207\right)$ to the total glyoxal in aqueous solution, the rate constants in Eq. (11) and Eq. (12) are connected by

$k_{\text {dimer,total }} \cdot 207=k_{\text {dimer }}$

resulting in $0.0035 \mathrm{M}^{-1} \mathrm{~s}^{-1}<k_{\text {dimer }}<1.2 \mathrm{M}^{-1} \mathrm{~s}^{-1}(3<\mathrm{pH}$ $<7)$. Using the equilibrium constant $\left(K_{\text {dimer }}=0.56 \mathrm{M}^{-1}\right.$, Fratzke and Reilly, 1986), the decay rate constant of the dimer is in a range of $0.006 \mathrm{~s}^{-1}<k_{\text {dimer }}^{\prime}<2 \mathrm{~s}^{-1}$ over this $\mathrm{pH}$ range.

\subsubsection{Effective glyoxal partitioning into $\left(\mathrm{NH}_{4}\right)_{2} \mathrm{SO}_{4}$ seed: formation of oligomers and other high molecular weight products}

Dark reactions of glyoxal in $\left(\mathrm{NH}_{4}\right)_{2} \mathrm{SO}_{4}$ solutions form glyoxal trimers or larger oligomers and other high molecular weight products. Aerosol mass spectrometer (AMS) and UV/vis absorption spectra of the resulting SOA mass show that the main fraction of products are exclusively composed of carbon, hydrogen and oxygen, i.e., they do not contain any heteroatoms (Galloway et al., 2009; Shapiro et al., 2009). Reaction times of several days revealed additional products with even more glyoxal monomer units. The glyoxal uptake calculated from these experiments was higher by some orders of magnitude than uptake into pure water (Kroll et al., 2005; Galloway et al., 2009; Ip et al., 2009; Volkamer et al., 2009). Experiments conducted in the dark (Kroll et al., 2005, Galloway et al., 2009) reached an equilibrium state, i.e., no further increase in organic aerosol mass was observed after several hours. Upon dilution of the reaction chamber, the organic-to-sulfate mass ratio decreased which implies a reversible mass formation mechanism (Galloway et al., 2009). The same oligomeric structures have been observed in experiments in ammonium solutions (Noziere et al., 2009a, b); the reaction mechanism suggested in that study implies a catalytic role of ammonium by acting as a Bronsted acid. Small contributions of C-N containing compounds cannot be ex- cluded based on these experiments and have been identified as direct reaction products of the ammonium ion and glyoxal (Sect. 3.3.2).

In Table 3, effective Henry's law constants $K_{\mathrm{H}}^{*}$ from various studies in seed particles are summarized. The values do not show any trends for different experimental conditions (RH, solute concentration etc.). The comparison of $K_{\mathrm{H}}^{*}$ and $K_{\text {Heff,hydr }}$ shows that the former is about 1000 times larger which yields $K_{\text {olig }}=1000$ (Eq. 5). This value suggests that 1000 times more oligomers are present than monomer glyoxal and is considerably higher than the estimate of $10 \%$ glyoxal oligomers (corresponding to $K_{\text {olig }} \sim 0.1$ ) assumed in a recent modeling study that explored particle phase processes (Pun and Seigneur, 2007) which was based on laboratory experiments for chemical systems different than glyoxal (Gao et al., 2004).

\subsubsection{Kinetic treatment of oligomerization in $\left(\mathrm{NH}_{4}\right)_{2} \mathrm{SO}_{4}$ seed}

A chemistry box model is applied to simulate the timedependent formation of glyoxal oligomers $\left(k_{\text {olig }}\right.$, Fig. 1) as observed in dark experiments by Volkamer et al. (2009). These experiments had reasonably good time-resolution and were performed over relatively short time scales ( $\sim 40 \mathrm{~min})$ before equilibrium was reached. The model includes a chemical scheme describing glyoxal uptake from the gas into the particle phase and Reactions (R1) and (R2) (Table 2) and has been initialized with the experimental conditions $(\mathrm{RH}$, aerosol loading and composition). It has been assumed that the observed volume increase is only due to the formation of organic mass with a density of $2 \mathrm{~g} \mathrm{~cm}^{-3}$, and the mass formation occurs by the reaction of glyoxal monohydrate with total glyoxal (mono-, dihydrate or unhydrated Reaction R3). Glyoxal monohydrate is assumed to be the reactive species since (i) it has an unhydrated aldehyde group that can undergo addition reactions and (ii) it is 350 times more abundant than the unhydrated glyoxal. The resulting rate constant that reproduces the measured volume increase due to organic 
mass formation in the experiments is $k_{\text {olig }}=100 \mathrm{M}^{-1} \mathrm{~s}^{-1}$. Together with the equilibrium constant $K_{\text {olig }}=1000$, the effective rate constant for the decay of oligomers is determined as $k^{\prime 2 \text { nd }}{ }_{\text {olig }}=k_{\text {olig }} / K_{\text {olig }}=0.1 \mathrm{M}^{-1} \mathrm{~s}^{-1}$ which translates into a first-order rate constant of $k_{\text {olig }}^{\prime} \sim 5.5 \mathrm{~s}^{-1}\left(\left[\mathrm{H}_{2} \mathrm{O}\right]=55 \mathrm{M}\right)$. The order of magnitude of this value agrees with $k_{\text {dimer }}^{\prime}$ based on (Fratzke and Reilly, 1986) ( $k_{\text {dimer }}(\mathrm{pH} \sim 5.5) \sim 2 \mathrm{~s}^{-1}$, Sect. 3.2.2). While Fratzke and Reilly (1986) only describe the decay of the dimer, the parameters $K_{\text {olig }}, k_{\text {olig }}$, and $k_{\text {olig }}^{\prime}$ represent lumped values that include possibly multiple oligomerization steps. The fact that the rate constants $k_{\text {dimer }}^{\prime}$ and $k_{\text {olig }}^{\prime}$ agree reasonably well suggests that the decay rate constant of higher oligomers (trimer, tetramer, etc) is on the same order of magnitude as that for the dimer.

In Fig. 2, the formation rate of oligomers is shown using these parameters $\left(k_{\text {olig }}, k_{\text {olig }}^{\prime}\right)$ and including the hydration constants $\left(k_{\text {hydr1 }}, k_{\text {hydr1 }}^{\prime}, k_{\text {hydr2 } 2}, k_{\text {hydr2 }}^{\prime}\right)$. The equilibrium for both the (di)hydrate and oligomer formation is reached after $\sim 3-4 \mathrm{~h}$. This is in excellent agreement with even longer experiment times that showed an increase in mass formation for about three hours and a constant mass concentration afterwards (Kroll et al., 2005; Galloway et al., 2009).

\subsubsection{Effective partitioning of glyoxal into aqueous $\mathrm{NaCl}$ seed particles}

Corrigan et al., (2008) and Ip et al. (2009) have investigated the partitioning of glyoxal into aqueous $\mathrm{NaCl}$ seed particles at different salt concentrations. In these studies, no kinetic information was reported so only the equilibrium constant $K_{\text {olig }}$ can be determined. The experiments show a less pronounced increase in glyoxal uptake as compared to aqueous $\left(\mathrm{NH}_{4}\right)_{2} \mathrm{SO}_{4}$ particles. The reported $K_{\mathrm{H}}{ }^{*}$ values (converted into molar units) are higher by factors of 4-6 compared to uptake on pure water (Ip et al., 2009) resulting in $3<K_{\text {olig }}<5$ on $\mathrm{NaCl}$ seed (Table 3). Notably, the conversion of the original data by Ip et al. (2009) from molar into molal units gives two $K_{\mathrm{H}}{ }^{*}$ values that do not show any dependence on the solute concentration, in agreement with data for ammonium sulfate seeds. Experiments on nearly dry, solid $\mathrm{NaCl}$ particles ( $\mathrm{RH} \sim 16 \%$, water content $\sim 2 \%$ ) have been interpreted as glyoxal uptake onto an aqueous layer rather than processes in a bulk solution (Corrigan et al., 2008) and thus no $K_{\text {olig }}$ are reported in Table 3.

\subsubsection{Effective partitioning of glyoxal into aqueous $\mathrm{Na}_{2} \mathrm{SO}_{4}$ seed particles}

Similar experiments have been performed on $\mathrm{Na}_{2} \mathrm{SO}_{4}$ particles (Corrigan et al., 2008; Ip et al., 2009). At a concentration of $\left[\mathrm{Na}_{2} \mathrm{SO}_{4}\right]=0.01 \mathrm{M}$ ( $\sim$ dilute droplets), $K_{\mathrm{H}}{ }^{*}=2.4 \times 10^{7} \mathrm{~mol} \mathrm{~kg}_{\mathrm{H}_{2} \mathrm{O}}{ }^{-1} \mathrm{~atm}^{-1}$ has been determined. At higher solute concentrations $(0.15 \mathrm{M}$; $\mathrm{RH}>95 \%)$, $K_{\mathrm{H}}{ }^{*}$ values exceeded $10^{9} \mathrm{~mol} \mathrm{~kg}_{\mathrm{H}_{2} \mathrm{O}}{ }^{-1} \mathrm{~atm}^{-1}$ (Ip et al., 2009). The very efficient glyoxal uptake on

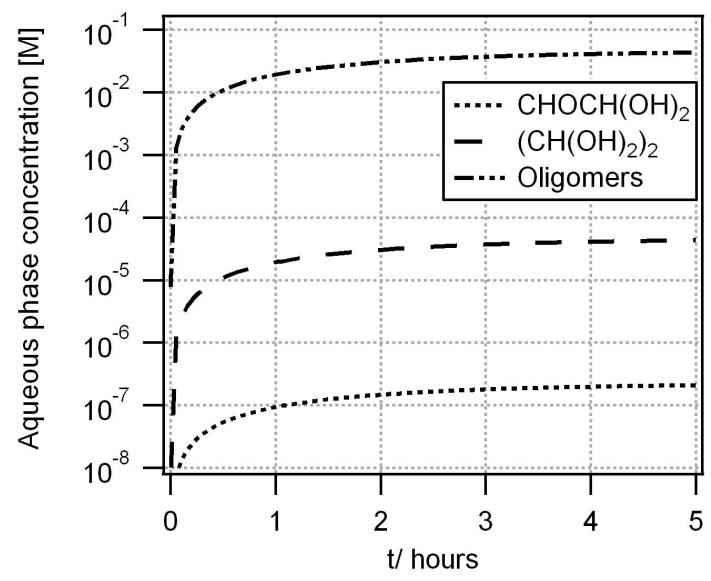

Fig. 2. Predicted concentration profiles glyoxal monohydrate $\mathrm{CHOC}(\mathrm{OH})_{2}$, dihydrate $\left(\mathrm{CH}(\mathrm{OH})_{2}\right)_{2}$ and oligomers as a function time. The time scale to reach equilibrium is due to the kinetics of the hydration processes $\left(k_{\mathrm{hydr} 1}, k_{\mathrm{hydr} 1}^{\prime}, k_{\mathrm{hydr} 2}, k_{\mathrm{hydr} 2}^{\prime}\right)$ and the oligomerization $\left(K_{\text {olig }}=k_{\text {olig }} / k_{\text {olig }}^{\prime}\right.$; cf Sects. 2.2 and 3.2.3).

$\mathrm{Na}_{2} \mathrm{SO}_{4}$ particles has been confirmed by experiments at nearly dry conditions $(\mathrm{RH}=15 \%)$ with a lower limit of $K_{\mathrm{H}}^{*}>3 \times 10^{8} \mathrm{~mol} \mathrm{~kg}_{\mathrm{H}_{2} \mathrm{O}}{ }^{-1} \mathrm{~atm}^{-1}$ (Corrigan et al., 2008) and translate into $K_{\text {olig }}>700$. For completeness, these lower limits of $K_{\mathrm{H}}{ }^{*}$ and $K_{\text {olig }}$ on $\mathrm{Na}_{2} \mathrm{SO}_{4}$ particles are listed in Table 3. Even though glyoxal interactions with $\mathrm{Na}_{2} \mathrm{SO}_{4}$ might not be of great atmospheric relevance, the comparison of data in Table 3 shows that the nature of the seed aerosol impacts glyoxal uptake in a complex way. However, the paucity of data on different seeds means that this effect cannot be systematically evaluated yet.

\subsection{Irreversible glyoxal uptake}

\subsubsection{Photochemical processes}

\section{Experimental evidence}

The oxidation of glyoxal by the $\mathrm{OH}$ radical in aqueous solution is nearly diffusion-controlled $\left(k_{\mathrm{OH}}=1.1 \times 10^{9} \mathrm{M}^{-1} \mathrm{~s}^{-1}\right)$ (Buxton et al., 1997; Ervens et al., 2003b). OH-reactions are the main loss of glyoxal in cloud droplets since the photolysis of the glyoxal dihydrate (tetrol) is unlikely. Under dilute conditions, the half-life of glyoxal towards the $\mathrm{OH}$ radical in aqueous solution is on the order of hours (assuming $[\mathrm{OH}]_{\mathrm{aq}} \sim 10^{-13} \mathrm{M}$, Ervens et al., 2003a), and products include glyoxylic, glycolic and oxalic acids (Carlton et al., 2007). With increasing glyoxal concentrations - simulating the transition from dilute droplets to slightly higher concentrated solutions $(\mu \mathrm{M}-\mathrm{mM})$ - the formation of high molecular weight, oligomeric compounds has been observed (Tan et al., 2009; Lim et al., 2010). Electrospray ionization mass spectrometry (ESI-MS) spectra showed that the structures of these oligomers differ from the products that have been 
Table 4. Reaction scheme used to assess the fate of organic peroxy radicals $\left(\mathrm{RO}_{2}\right)$ in the aqueous phase of cloud droplets and aerosol particles (Fig. 6); $\mathrm{R}^{(I I)} \mathrm{O}_{2}, \mathrm{R}^{(I I)} \mathrm{OOR}^{(I I)}, \mathrm{R}^{(I I)} \mathrm{OOH}$ denote the sum of all organic peroxy radicals, organic peroxides and organic hydroperoxides, respectively.

\begin{tabular}{|c|c|c|c|c|}
\hline Uptake & \multicolumn{4}{|c|}{$\begin{array}{c}\text { Henry's law constants } K_{\mathrm{H}} \\
\text { mass accommodation } \alpha \\
\text { gas phase diffusion } D_{\mathrm{g}} \text { coefficients }\end{array}$} \\
\hline $\mathrm{R}$ (gas) & $\rightleftharpoons$ & $\mathrm{R}$ & \multirow{4}{*}{$\begin{array}{l}K_{\mathrm{H}}=4.2 \times 10^{5} \mathrm{M} \mathrm{atm}^{-1} \\
\alpha=0.023 ; D_{\mathrm{g}}=1.15 \times 10^{5} \mathrm{~m}^{2} \mathrm{~s}^{-1} \\
K_{\mathrm{H}}=25 \mathrm{M} \mathrm{atm}^{-1} \\
\alpha=0.05 ; D_{\mathrm{g}}=1.53 \times 10^{5} \mathrm{~m}^{2} \mathrm{~s}^{-1} \\
K_{\mathrm{H}}=1.2 \times 10^{5} \mathrm{M} \mathrm{atm}^{-1} \\
\alpha=0.11 ; D_{\mathrm{g}}=1.46 \times 10^{5} \mathrm{~m}^{2} \mathrm{~s}^{-1} \\
K_{\mathrm{H}}=9000 \mathrm{M} \mathrm{atm} \\
\alpha=0.01 ; D_{\mathrm{g}}=1.04 \times 10^{5} \mathrm{~m}^{2} \mathrm{~s}^{-1}\end{array}$} & $\begin{array}{l}\text { Ip et al., } 2009 \\
\text { Ervens et al., 2003a }\end{array}$ \\
\hline $\mathrm{OH}$ (gas) & $\rightleftharpoons$ & $\mathrm{OH}$ & & $\begin{array}{l}\text { Kläning et al., } 1985 \\
\text { Hanson et al., } 1992\end{array}$ \\
\hline $\mathrm{H}_{2} \mathrm{O}_{2}$ (gas) & $\rightleftharpoons$ & $\mathrm{H}_{2} \mathrm{O}_{2}$ & & $\begin{array}{l}\text { Lind and Kok, } 1994 \\
\text { Davidovits et al., 1995; McElroy, } 1997\end{array}$ \\
\hline $\mathrm{HO}_{2}$ (gas) & $\rightleftharpoons$ & $\mathrm{HO}_{2}$ & & $\begin{array}{l}\text { Weinstein-Lloyd and Schwartz, } 1991 \\
\text { Hanson et al., } 1992\end{array}$ \\
\hline \multicolumn{3}{|c|}{ Aqueous phase reactions } & \multicolumn{2}{|l|}{$k$} \\
\hline \multicolumn{5}{|l|}{ Oxidation } \\
\hline $\mathrm{R}+\mathrm{OH}\left(+\mathrm{O}_{2}\right)$ & $\rightarrow$ & $\mathrm{RO}_{2}+\mathrm{H}_{2} \mathrm{O}$ & $10^{9} \mathrm{M}^{-1} \mathrm{~s}^{-1}$ & Order of magnitude of $k(\mathrm{OH}+\mathrm{glyoxal})$ Ervens et al., 2003b \\
\hline $\mathrm{RO}_{2}$ & $\rightarrow$ & $\mathrm{R}^{\mathrm{I}}+\mathrm{HO}_{2}$ & $\begin{array}{l}10^{5} \mathrm{~s}^{-1^{\mathrm{a}}} \\
10^{2} \mathrm{~s}^{-1^{\mathrm{a}}}\end{array}$ & $k\left(\mathrm{CH}(\mathrm{OH})_{2} \mathrm{O}_{2}\right)$ Neta et al., 1990 \\
\hline $\mathrm{R}^{\mathrm{I}}+\mathrm{OH}\left(+\mathrm{O}_{2}\right)$ & $\rightarrow$ & $\mathrm{R}^{\mathrm{I}} \mathrm{O}_{2}+\mathrm{H}_{2} \mathrm{O}$ & $10^{8} \mathrm{M}^{-1} \mathrm{~s}^{-1}$ & Order of magnitude of $k(\mathrm{OH}+$ glyoxylic acid $)$ Ervens et al., 2003b \\
\hline $\mathrm{R}^{\mathrm{I}} \mathrm{O}_{2}$ & $\rightarrow$ & $\mathrm{R}^{\mathrm{II}}+\mathrm{HO}_{2}$ & $\begin{array}{l}10^{5} \mathrm{~s}^{-1^{\mathrm{a}}} \\
10^{2} \mathrm{~s}^{-1^{\mathrm{a}}}\end{array}$ & $k\left(\mathrm{CH}(\mathrm{OH})_{2} \mathrm{O}_{2}\right)$ Neta et al., 1990 \\
\hline $\begin{array}{l}\mathrm{R}^{\mathrm{II}}+\mathrm{OH}\left(+\mathrm{O}_{2}\right) \\
\text { Decay of peroxy ra }\end{array}$ & $\rightarrow$ & $\mathrm{R}^{\mathrm{II}} \mathrm{O}_{2}+\mathrm{H}_{2} \mathrm{O}$ & $10^{7} \mathrm{M}^{-1} \mathrm{~s}^{-1}$ & Order of magnitude of $k(\mathrm{OH}+$ oxalic acid) Ervens et al., 2003b \\
\hline $\mathrm{R}^{\mathrm{II}} \mathrm{O}_{2}$ & $\rightarrow$ & $\mathrm{CO}_{2}+\mathrm{HO}_{2}$ & $\begin{array}{l}10^{5} \mathrm{~s}^{-1^{\mathrm{a}}} \\
10^{2} \mathrm{~s}^{-1^{\mathrm{a}}}\end{array}$ & $\begin{array}{l}k\left(\mathrm{CH}(\mathrm{OH})_{2} \mathrm{O}_{2}\right) \text { Neta et al., } 1990 \\
k\left(\mathrm{CH}_{2}(\mathrm{OH}) \mathrm{CH}(\mathrm{OH}) \mathrm{O}_{2}\right) \text { Neta et al., } 1990\end{array}$ \\
\hline \multicolumn{5}{|c|}{ Recombination reactions } \\
\hline $\mathrm{R}^{(\mathrm{II})} \mathrm{O}_{2}+\mathrm{HO}_{2}$ & $\rightarrow$ & $\mathrm{R}^{(\mathrm{II})} \mathrm{OOH}+\mathrm{O}_{2}^{\mathrm{b}}$ & $10^{9} \mathrm{M}^{-1} \mathrm{~s}^{-1}$ & Estimated based on Schuchmann et al., 1985 \\
\hline $\mathrm{R}^{(\mathrm{II})} \mathrm{O}_{2}+\mathrm{R}^{(\mathrm{II})} \mathrm{O}_{2}$ & $\rightarrow$ & $\mathrm{R}^{(\mathrm{II})} \mathrm{OOR}^{(\mathrm{II})}+\mathrm{O}_{2}^{\mathrm{b}}$ & $10^{9} \mathrm{M}^{-1} \mathrm{~s}^{-1}$ & Estimated based on Schuchmann et al., 1985 \\
\hline $\mathrm{HO}_{2}+\mathrm{HO}_{2}$ & $\rightarrow$ & $\mathrm{H}_{2} \mathrm{O}_{2}+\mathrm{O}_{2}$ & $9.7 \times 10^{7} \mathrm{M}^{-1} \mathrm{~s}^{-1}$ & $\begin{array}{l}\text { Bielski et al., 1985; Rate constant for } \mathrm{O}_{2}^{-}+\mathrm{HO}_{2} \text { to simulate } \\
\text { atmospheric relevant } \mathrm{pH} \text { regime }\end{array}$ \\
\hline $\mathrm{R}\left({ }^{\mathrm{II}}\right) \mathrm{OOH}+\mathrm{OH}$ & $\rightarrow$ & $\mathrm{R}^{(\mathrm{II})} \mathrm{O}_{2}+\mathrm{H}_{2} \mathrm{O}$ & $2.4 \times 10^{7}$ & Estimated as fraction of $k\left(\mathrm{H}_{2} \mathrm{O}_{2}+\mathrm{OH}\right)$ Ervens et al., 2003a \\
\hline $\mathrm{HO}_{2}+\mathrm{OH}$ & $\rightarrow$ & $\mathrm{H}_{2} \mathrm{O}+\mathrm{O}_{2}$ & $1.1 \times 10^{10}$ & Elliot and Buxton, 1992 \\
\hline \multicolumn{5}{|l|}{$\mathrm{HO}_{\mathrm{x}}$ conversion } \\
\hline $\mathrm{H}_{2} \mathrm{O}_{2}+\mathrm{OH}$ & $\rightarrow$ & $\mathrm{HO}_{2}+\mathrm{H}_{2} \mathrm{O}$ & $3 \times 10^{7}$ & Christensen et al., 1982 \\
\hline
\end{tabular}

${ }^{\text {a }}$ See Fig. 3a-c and Fig. 3d-f for sensitivity study for this rate constant; ${ }^{b}$ no other products of the recombination reactions are considered due to the lack of appropriate data.

identified under dark conditions and in the absence of $\mathrm{OH}$. It is suggested that they are formed through a radical-initiated mechanism since they are composed of oxidation products of glyoxal, e.g. glyoxylic acid and oxalic acid.

First evidence that photochemistry of glyoxal enhances the rate of SOA formation in aqueous aerosols was presented by Volkamer et al. (2009). They observed that in the presence of $\mathrm{OH}$ radicals and UV light, the rate of volume growth from glyoxal was 2-3 orders of magnitude faster as compared to the volume growth due to organic mass formation under dark conditions. They further found a seed effect on SOA yields, and demonstrated that under variable RH conditions and for aqueous seeds (ammonium sulfate, ammonium bisulfate, fulvic acid and mixtures of ammonium sulfate/fulvic acid) the yields scaled with the LWC of the particles. The much slower SOA formation rate in absence of an $\mathrm{OH}$ radical source (Galloway et al., 2009) and the findings by Volkamer et al. (2009) and Tan et al. (2009) suggest that indeed a radical-initiated process (or several processes) are likely to accelerate SOA formation by glyoxal multiphase photochemistry in particles. It can be concluded that the reaction mechanism in atmospheric aqueous particles proceeds via different reactions than in (dilute) cloud droplets, and forms product patterns that are much more complex. In particular, it is not expected that simple scaling of dilute cloud chemistry by the difference in LWC can describe the chemistry in concentrated aerosol aqueous phase.

\section{Differences in peroxy radical chemistry in dilute and concentrated solutions}

In Table 4, a schematic reaction mechanism of the multiphase oxidation of an organic compound " $\mathrm{R}$ " by the $\mathrm{OH}$ radical is presented where $\mathrm{R}$ has properties similar to glyoxal. While the uptake of water-soluble gases should result in the same aqueous phase concentrations (thermodynamic equilibrium, 
Henry's law constants), further chemical processing in the aqueous phase might lead to different products if nonvolatile species are formed. Thermodynamic equilibrium might be only reached upon the kinetic time scale of the uptake and if aqueous phase loss rates are slow enough to compensate continuous transport from the gas phase. These species accumulate in the aqueous phase and build up higher concentrations more quickly in the small particle volumes. Each oxidation step includes the formation of an intermediate peroxy radical $\left(\mathrm{RO}_{2}, \mathrm{R}^{\mathrm{I}} \mathrm{O}_{2}, \mathrm{R}^{\mathrm{II}} \mathrm{O}_{2}\right)$. These radicals either decay to the oxidation product and $\mathrm{HO}_{2}$ (von Sonntag and Schuchmann, 1991) or recombine with $\mathrm{HO}_{2}$ or $\mathrm{RO}_{2}$. While the decay leads to oxidation products $\left(\mathrm{R}^{\mathrm{I}}, \mathrm{R}^{\mathrm{II}}\right)$, the accumulation of peroxy radicals in a smaller water volume favors the recombination in aqueous particles. The recombination of any organic peroxy radical leads to an increase in carbon atoms in the products with oligomer-like structures.

For model simulations using the mechanism in Table 4, constant gas phase precursor concentration $[R]_{\text {gas }}=300 \mathrm{ppt}$; $[\mathrm{OH}]_{\mathrm{gas}}=5 \times 10^{6} \mathrm{~cm}^{-3}$ are assumed that are typical for urban environments. In Fig. 3, concentration profiles are shown for oxidation products and $\mathrm{RO}_{2}$ recombination products for typical conditions in cloud droplets and aqueous particles based on the simplified scheme in Table 4. These results suggest that the physical differences listed in Table 1 favor the formation of organic peroxides $\mathrm{R}^{(\mathrm{II})} \mathrm{OOR}^{(\mathrm{II})}$ in particles. The literature values for the decay rate constant for organic hydroxy peroxy radicals differ by several orders of magnitude (Neta et al., 1990) (Table 4). In order to explore this parameter, Fig. 3a-c and $\mathrm{d}-\mathrm{f}$ compare resulting concentration profiles for decay rates of $10^{5} \mathrm{~s}^{-1}$ and $10^{2} \mathrm{~s}^{-1}$, respectively. The concentration levels of $\mathrm{R}^{(\mathrm{II})} \mathrm{OOR}^{(\mathrm{II})}$ and $\mathrm{R}^{(\mathrm{II})} \mathrm{OOH}$ are significantly impacted which demonstrates that the lifetime of the peroxy radicals in aerosol water is a sensitive parameter that is currently poorly constrained by experiments. The concentration levels of the peroxides $\mathrm{R}^{(\mathrm{II})} \mathrm{OOR}^{(\mathrm{II})}$ and $\mathrm{R}^{(\mathrm{II})} \mathrm{OOH}$ should be regarded as upper limits since it is assumed that they are exclusively formed by the recombination reactions, and pathways that do not lead to the termination of the radical chain are not considered due to the poor knowledge on peroxy radical chemistry in the aqueous phase. Another result from Fig. 4 is that the $\mathrm{OH}$ radical concentration in aqueous aerosols, in contrast to clouds, does not experience any significant kinetic barrier towards uptake of $\mathrm{OH}$ radicals from the gas phase. This results in aqueous phase $\mathrm{OH}$ radical concentrations that are about two orders of magnitude higher than in cloud water, leading to accordingly greater rates of $\mathrm{RO}_{2}$ radical production, and much greater formation rates of stable products in aerosol water.

\subsubsection{Numerical simulation of photochemical chamber experiments}

In order to empirically derive the total SOA formation efficiency of all reactions that lead to products other than the
$\mathrm{OH}$-oxidation products, box model simulations have been performed to derive kinetic parameters for the organic mass formation rates as observed in photochemical experiments (Volkamer et al., 2009). The model has been initialized with the experimental conditions (glyoxal, OH concentrations, $\mathrm{RH}$, mass loading). The water content of the seed aerosol has been calculated by the aerosol inorganic model (AIM) (Clegg and Brimblecombe, 1998). Two different assumptions have been made for simulations A and B (see below) regarding the hygroscopicity of the newly formed organic mass: (i) the mass is not hygroscopic and the observed volume increase is only due to organic mass formation, (ii) the newly formed organic mass has a hygroscopicity parameter $\kappa=0.24$ (Petters and Kreidenweis, 2007). This value corresponds to a compound with molecular weight $M=150 \mathrm{~g} \mathrm{~mol}^{-1}$ (e.g., mixture of glyoxal dimers and trimers) and a density of $2 \mathrm{~g} \mathrm{~cm}^{-3}$ (Volkamer et al., 2009), which are roughly in agreement with other highly oxygenated SOA constituents. In these model assumptions, the observed volume increase is due to organic mass formation and additional water uptake by this mass. The density of glyoxal trimer dihydrate is about $15 \%$ lower $\left(1.67-1.71 \mathrm{~g} \mathrm{~cm}^{-3}\right.$ ) (De Haan et al., 2009b; Galloway et al., 2009), and use of this smaller density results in a slightly larger volume prediction by the model. While the density of SOA from glyoxal is currently not well known, it is not regarded a major uncertainty in the model. In the simulations, effects of highly concentrated solutions are simulated in detail and activity coefficients of unity are assumed. It should be noted that the current approach does not claim to fully account for the underlying physical and chemical processes but it is rather an empirical representation of such processes in models based on the current knowledge in glyoxal reactivity. Refinements on the proposed parameters should be made as more systematic laboratory data becomes available.

In order to relate experimentally observed SOA mass to the known oxidation chemistry in the aqueous phase, the simulations using the reaction scheme in Table 4 have been repeated for experimental conditions ([Glyoxal $]_{\mathrm{gas}}=160 \mathrm{ppb}$; $\left.[\mathrm{OH}]=2.2 \times 10^{7} \mathrm{~cm}^{-3}\right)$. Figure $3 \mathrm{~g}-\mathrm{i}$ shows the predicted concentration profiles of radicals, oxidation products and recombination products of simulations using $\mathrm{OH}$ and glyoxal concentrations similar to those in the experiments. Due to the high glyoxal concentration, $\mathrm{OH}$ is rapidly consumed in the aqueous phase resulting in a concentration that is about an order of magnitude lower than its equilibrium concentration. Even if the $\mathrm{OH}$ transport into the aqueous phase was not limited, i.e. thermodynamic equilibrium was reached at any given time, the products could not explain the SOA volumes of $\sim 10 \mu \mathrm{m}^{3} \mathrm{~cm}^{-3}$ as observed in the $\sim 5$ min-long experiments (additional scale in Fig. 3h and i) (Volkamer et al., 2009).

There are two conclusions from Fig. 3: first, $\mathrm{RO}_{2}$ radicals undergo essentially different reaction pathways in concentrated aerosol water than in more dilute cloud droplets. Radical-radical self reactions become important in aerosol 
Radicals

I. [Gly] $=300 \mathrm{ppt}$
$[\mathrm{OH}]=5 \cdot 10^{6} \mathrm{~cm}^{-3}$

$\mathrm{RO}_{2} \rightarrow \mathrm{CO}_{2}+\mathrm{HO}_{2}$
$\mathrm{k}=10^{5} \mathrm{~s}^{-1}$

II. [Gly] $=300 \mathrm{ppt}$ $[\mathrm{OH}]=5 \cdot 10^{6} \mathrm{~cm}^{-3}$

$\mathrm{RO}_{2} \rightarrow \mathrm{CO}_{2}+\mathrm{HO}_{2}$ $\mathrm{k}=10^{2} \mathrm{~s}^{-1}$
III. [Gly] $=160 \mathrm{ppb}$ $[\mathrm{OH}]=2.2 \cdot 10^{7} \mathrm{~cm}^{-3}$ Reactions as in I. Size distributions as in experiments by Volkamer et al., 2009
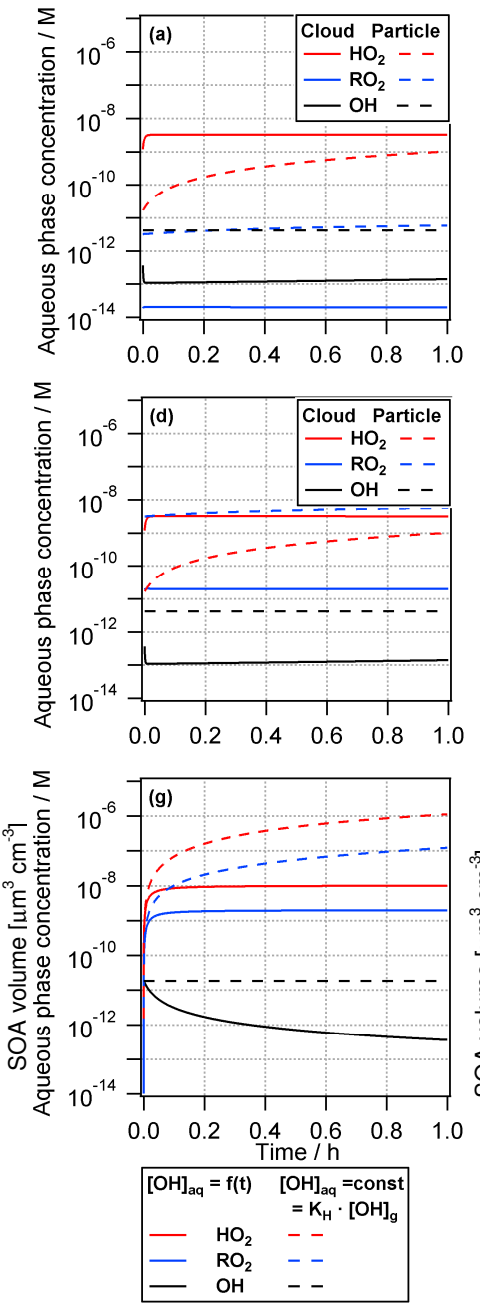

Stable oxidation products
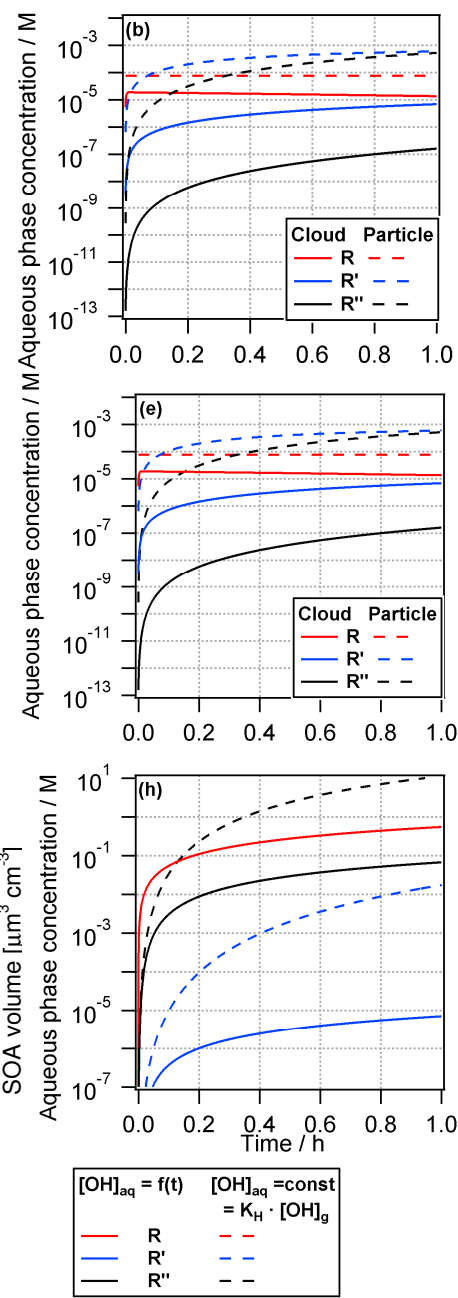

Recombination
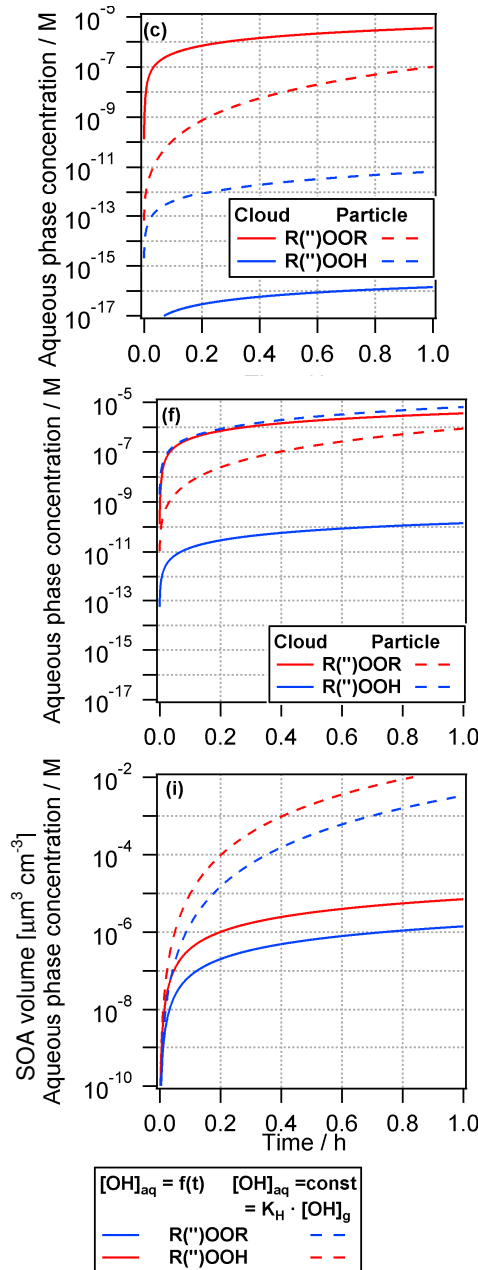

Fig. 3. Predicted concentration profiles of aqueous phase concentrations reactive intermediates (radicals) (a, d, g), stable oxidation products $(\mathbf{b}, \mathbf{e}, \mathbf{h})$ and recombination products $(\mathbf{c}, \mathbf{f}, \mathbf{i})$ simulated with the reaction scheme in Table 4. "Cloud" refers to dilute aqueous phase conditions with drop diameters $D=20 \mu \mathrm{m}, \mathrm{LWC}=0.4 \mathrm{~g} \mathrm{~m}^{-3}, N_{\text {droplets }}=100 \mathrm{~cm}^{-3}$; "particle" to a more concentrated aqueous phase with aqueous particles with diameters $D=100 \mathrm{~nm}, \mathrm{LWC}=20 \mu \mathrm{g} \mathrm{m}^{-3}, N_{\text {particles }}=5000 \mathrm{~cm}^{-3}$. Top panel (a-c): the decay rate of peroxy radicals has been assumed as $10^{5} \mathrm{~s}^{-1}$ (Table 4) (Neta et al., 1990). Middle panel (d-f): the decay rate of peroxy radicals has been assumed as $10^{2} \mathrm{~s}-1$ (Table 4 ) (Neta et al., 1990). Bottom panel (g-i): same mechanism and rate constants as for top panel but initial gas phase concentrations as used in experiments by Volkamer et al. (2009) ([Glyoxal $\left.]_{\mathrm{gas}}=160 \mathrm{ppb} ;[\mathrm{OH}]_{\mathrm{gas}}=2.2 \times 10^{7} \mathrm{~cm}^{-3}\right)$. $[\mathrm{OH}]_{\mathrm{aq}}=f(t)$ includes the kinetic description of $\mathrm{OH}$ transfer into the aqueus phase (as used for all other simulations); $[\mathrm{OH}]_{\mathrm{aq}}=$ const. assumes a constant $\mathrm{OH}$ concentration that implies thermodynamic equilibrium with the gas phase at all times $[\mathrm{OH}]_{\mathrm{aq}}=K_{\mathrm{H}}(\mathrm{OH}) \cdot[\mathrm{OH}]_{\text {gas }}($ Sect. 3.3.1).

water. Second, the observed SOA is not mainly composed of the products suggested by the reaction scheme in Table 4 but other products predominate. Such additional products likely include high molecular weight species (oligomers) such as those that have been identified in recent studies (Tan et al., 2009; Lim et al., 2010) and their formation is not included in the scheme in Table 4. It is evident that the concentration of SOA products $\left(\mathrm{R}^{\mathrm{I}}, \mathrm{R}^{\mathrm{II}}, \mathrm{R}^{(\mathrm{II})} \mathrm{OOR}^{(\mathrm{II})}\right)$ increases with a higher $\mathrm{OH}$ concentration. However, the Henry's law constant for $\mathrm{OH}$ in aqueous particles is not well known; for cloud water four values that have been derived based on thermodynamical calculations show a narrow range of $25 \mathrm{M} \mathrm{atm}^{-1}<K_{\mathrm{H}}(\mathrm{OH})<32 \mathrm{M} \mathrm{atm}^{-1}$ (Sander, 1999 (last access, April 2010)). It is unlikely that the significant underestimate of SOA mass in aerosols is due uncertain partitioning of $\mathrm{OH}$. It is rather suggested that (an) additional process(es) occur(s) in aerosols not captured by the reactions in Table 4. 
Table 5. Parameters of linear correlations of predicted vs. observed (Volkamer et al., 2009) SOA volumes (Fig. 4) for pure ammonium sulfate and ammonium sulfate/fulvic acid seed and different assumptions about SOA hygroscopicity. The model to predict SOA mass only includes $\mathrm{OH}(\mathrm{aq})+\mathrm{Gly}(\mathrm{aq})$ reactions as applied to dilute aqueous conditions (cf Simualtion A in Sect. 3.3.1). $V_{\mathrm{SOA}}(\mathrm{observed})^{\mathrm{a}}=a+b \cdot\left[V_{\mathrm{SOA}}\right.$ model(OH reaction)]; correlation coefficients $R^{2}$ and number of experiments $n$.

\begin{tabular}{llllll}
\hline Seed aerosol & & $a$ & $b$ & $R^{2}$ \\
\hline \multirow{2}{*}{ Ammonium sulfate } & Non-hygroscopic SOA & $n=4$ & 1.6 & 720 & 0.60 \\
& Hygroscopic SOA & & 1 & 290 & 0.82 \\
Ammonium sulfate/Fulvic acid & Non-hygroscopic SOA & $n=6$ & 5.1 & 2250 & 0.72 \\
& Hygroscopic SOA & & 0.95 & 870 & 0.86 \\
\hline
\end{tabular}

${ }^{a} V_{\text {SOA }}$ from experiments by Volkamer et al. (2009)

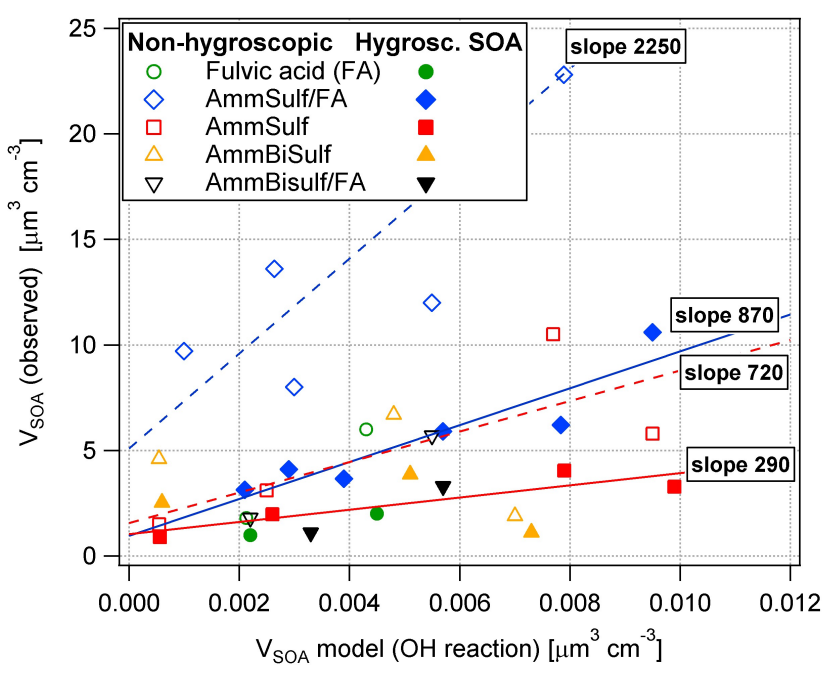

Fig. 4. Comparison of observed volume increase in photochemical experiments (Volkamer et al., 2009) and predicted volume increase due to the aqueous phase reaction of glyoxal and $\mathrm{OH}$ (Reaction R5, Table 2, Sect. 3.3.1 "Simulation A") as previously applied to dilute aqueous phase conditions ("cloud droplets"). Open symbols (non-hygroscopic SOA) imply that the observed volume increase was only due to SOA formation; filled symbols (hygroscopic SOA) refer to the assumption that observed volume increase is caused by formation of hygroscopic SOA and additional water uptake by this mass.

\subsubsection{Numerical description of additional photochemical process(es)}

Simulation A. In order to numerically describe chamber experiments of glyoxal uptake into particles, in a first step, a box model has been applied that only included "cloud chemistry", i.e., glyoxal dissolution, and its reaction with $\mathrm{OH}_{(\mathrm{aq})}$ (Reaction R5). It has been assumed that the total glyoxal concentration (which is $>99 \%$ composed of glyoxal dihydrate) reacts with $\mathrm{OH}$. For simplicity, it was assumed that glyoxal oxidation yields $100 \%$ non-volatile products. This is compatible with laboratory experiments, where most of the initial total organic carbon was conserved in the bulk wa- ter phase (Tan et al., 2009). In Fig. 4, the predicted organic aerosol volume is compared to the observed volumes in the experiments. Results are shown for both hygroscopicity assumptions $\left(\kappa_{\text {org }}=0 ; \kappa_{\text {org }}=0.24\right)$ of the newly formed organic mass.

In order to quantify the discrepancy between SOA predicted by the $\mathrm{OH}$ reaction and observed SOA, parameters of linear correlations for ammonium sulfate and ammonium sulfate/fulvic acid seeds are summarized in Table 5. (For the other seeds only two or three experiments were available and a linear correlation might not be meaningful). The enhancement in the mixed ammonium sulfate/ fulvic acid particles is about a factor of three higher than in pure ammonium sulfate particles which points to an additional effect on SOA formation by fulvic acid. It is obvious that the direct reaction of $\mathrm{OH}$ radicals with glyoxal can only explain a small fraction $(<1 \%)$ of the observed SOA mass (slopes of linear correlations in Fig. 4). The predicted aqueous phase SOA is found to scale linearly with the observed SOA (Table 5). Assuming hygroscopic SOA mass, the small intercepts of the linear correlations $(0.95<\mathrm{a}<5.1)$, and good correlation coefficients $\left(R^{2}>0.8\right)$ suggest that SOA formation in aerosol water is indeed linked to $\mathrm{OH}$ chemistry. Notably, the calculations assuming hygroscopic SOA consistently show a smaller intercept, and a higher $R^{2}$ value, indicating that this scenario is more plausible.

It seems unlikely that the presence of high solute concentrations alters the kinetics of the glyoxal oxidation by $\mathrm{OH}$ (ionic strength effects) by the more than two orders of magnitude required to explain this discrepancy between the prediction of the "dilute aqueous phase chemistry" model and observed mass formation rates. Kinetic studies of similar systems (OH reaction with acetone, propanol or butanol) have shown that ionic strength effects can only account for an increase of a factor $\sim 2$ of the bimolecular rate constant $k_{\mathrm{OH}}$ (Herrmann, 2003). Instead of such effects, it is rather suggested that additional chemical processes occur that contribute to organic mass formation.

Simulation $B$. The model has been extended by an additional process $\left(k_{\text {photochem}}\right.$, Fig. 1) to account for the 
Table 6. Rate constants $k_{\text {photochem }}$ and reactive uptake coefficients $\gamma_{\text {photochem }}$ for the additional photochemical process that has been added to the box model to match observed and predicted SOA volume increase (Fig. 4a and c). "Exp" refers to the experiment numbers in the study by Volkamer et al. (2009). Simulation B and C are explained in Sect. 3.3.1. $k_{\text {photochem }}^{\text {average }} \gamma_{\text {photochem }}^{\text {average }}$ denote average values \pm standard deviation for each seed aerosol composition and hygroscopicity assumption of the newly formed SOA. Note that the parameters $k_{\text {photochem }}$ and $\gamma_{\text {photochem }}$ have been derived from photochemical experiments with high $\mathrm{OH}$ concentrations $\left(\geq 10^{7} \mathrm{~cm}^{-3}\right)$. It is likely that the reaction parameters are smaller at lower $\mathrm{OH}(h v)$ concentrations.

\begin{tabular}{|c|c|c|c|c|c|c|c|c|c|}
\hline & \multirow[b]{3}{*}{ Exp. } & \multicolumn{2}{|c|}{ Non-hygroscopic SOA } & \multicolumn{2}{|c|}{ Hygroscopic SOA } & \multicolumn{2}{|c|}{ Non-hygroscopic SOA } & \multicolumn{2}{|c|}{ Hygroscopic SOA } \\
\hline & & \multicolumn{4}{|c|}{ Bulk process: Simulation B } & \multicolumn{4}{|c|}{ Surface process: Simulation C } \\
\hline & & $\begin{array}{l}k_{\text {photochem }} \\
{\left[\mathrm{s}^{-1}\right]}\end{array}$ & $\begin{array}{l}k_{\text {photochem }}^{\text {average }} \\
{\left[\mathrm{s}^{-1}\right]}\end{array}$ & $\begin{array}{l}k_{\text {photochem }} \\
{\left[\mathrm{s}^{-1}\right]}\end{array}$ & $\begin{array}{l}k_{\text {photochem }}^{\text {average }} \\
{\left[\mathrm{s}^{-1}\right]}\end{array}$ & $\gamma_{\text {photochem }}$ & $\gamma_{\text {photochem }}^{\text {average }}$ & $\gamma_{\text {photochem }}$ & $\gamma_{\text {photochem }}^{\text {average }}$ \\
\hline \multirow[t]{2}{*}{ Fulvic acid } & 19 & 1.2 & $1.5 \pm 0.4$ & 0.7 & $0.8 \pm 0.1$ & & & & \\
\hline & 14 & 1.7 & & 0.8 & & & & & \\
\hline \multirow{4}{*}{$\begin{array}{l}\text { Ammonium } \\
\text { sulfate }\end{array}$} & 13 & 2 & $4 \pm 3$ & 1.1 & $2 \pm 1$ & & & & \\
\hline & 9 & 3 & & 1.5 & & & & & \\
\hline & 18 & 4.5 & & 2.2 & & & & & \\
\hline & 7 & 8 & & 2.8 & & & & & \\
\hline \multirow{6}{*}{$\begin{array}{l}\text { Ammonium } \\
\text { sulfate/fulvic } \\
\text { acid }\end{array}$} & 17 & 7.7 & $18 \pm 7$ & 3.2 & $7 \pm 3$ & 0.01 & $0.016 \pm 0.007$ & 0.005 & $0.008 \pm 0.003$ \\
\hline & 11 & 13 & & 6 & & 0.013 & & 0.006 & \\
\hline & 27 & 23 & & 9.4 & & 0.012 & & 0.012 & \\
\hline & 26 & 13.5 & & 5 & & 0.013 & & 0.0065 & \\
\hline & 12 & 25 & & 9.5 & & 0.017 & & 0.008 & \\
\hline & 20 & 23 & & 11.5 & & 0.03 & & 0.012 & \\
\hline Ammonium & 23 & 2.9 & $9 \pm 5$ & 1.6 & $4 \pm 2$ & & & & \\
\hline \multirow[t]{2}{*}{ Bisulfate } & 8 & 12.4 & & 5 & & & & & \\
\hline & 21 & 12 & & 6.3 & & & & & \\
\hline Amm Bisulfate/ & 24 & 1 & $5 \pm 5$ & 0.5 & $2 \pm 2$ & & & & \\
\hline Fulvic acid & 22 & 8.5 & & 4 & & & & & \\
\hline
\end{tabular}

"excess SOA" observed in the photochemical experiments by Volkamer et al. (2009) that cannot be explained by the model application as outlined in Simulation A. This rate constant is an empirical description of an additional process (or multiple processes) in the presence of $\mathrm{OH}$ and $h v$. It can as yet not unequivocally be decided if this process is actually driven by photons or $\mathrm{OH}$, or other radicals whose formation pathways might not be fully captured by the scheme in Table 4 . However, the linear correlations of predicted and observed SOA mass from $\mathrm{OH}$ chemistry (Fig. 4; Table 5) are consistent with a radical initiated process. For each experiment, the rate constant $k_{\text {photochem }}\left[\mathrm{s}^{-1}\right.$ ] was chosen to match the observed organic mass and thus to account for the discrepancy between the observed and predicted (assuming dilute aqueous phase chemical processes) SOA masses in Fig. 4 (Table 6). The resulting $k_{\text {photochem }}$ from the model simulations for hygroscopic SOA are about a factor of two smaller than those for non-hygroscopic SOA since (i) the observed volume growth is due to both organic mass formation and additional water and (ii) the additional water on the particles provides more volume where glyoxal can be taken up and react. The hygroscopicity of photochemical glyoxal-SOA is currently not known, and these model studies set bounds on the actual value of $k_{\text {photochem. }}$. Since it seems likely that glyoxal-SOA is indeed hygroscopic because of its highly oxidized state $(\mathrm{O} / \mathrm{C} \geq 1), k_{\text {photochem }}$ values that account for wa- ter uptake $(\kappa>0)$ seem more appropriate for atmospheric applications. The dependence of $k_{\text {photochem }}$ on the different seeds cannot be fully explained; however, some trends can be identified. While the comparison of $k_{\text {photochem }}\left(\left(\mathrm{NH}_{4}\right)_{2} \mathrm{SO}_{4}\right)$ and $k_{\text {photochem }}\left(\mathrm{NH}_{4} \mathrm{HSO}_{4}\right)$ suggests that the particle phase reaction is faster in more acidic conditions, this relationship breaks down for mixed particles composed of ammonium sulfate/fulvic acid and ammonium bisulfate/fulvic acid that exhibit the opposite trend in $k_{\text {photochem. }}$. The enhanced $k_{\text {photochem }}$ for mixed fulvic acid particles as compared to pure fulvic acid particles suggests that fulvic acid can react with glyoxal but pure fulvic acid particles contain too little water to fully dissolve. More laboratory work will be required to understand the trends of the reactivities in seed of different chemical composition.

The application of $k_{\text {photochem }}$ implies that the SOA mass is formed in the bulk aqueous phase of the particles (Eq. 6; Eq. 8). In Fig. 5a, the observed volume increase is shown as a function of the total water mass on the particles. This is similar to the discussion by Volkamer et al. (2009), however, here the volume increase only due to hygroscopic SOA mass is considered. For all seeds, a clear trend can be seen with correlation coefficients of $R^{2}=0.74$ and $R^{2}=0.52$ for ammonium sulfate and mixed ammonium sulfate/fulvic acid particles, respectively. The total solution volume does not seem to determine mass formation rates since the observed 
mass increase does not correlate with the total amount of seed (solute mass + water) (Fig. 5b). In Fig. 5c, the possibility that photochemical uptake is controlled by a surface-limited process is explored. For most seed types, there is no correlation with aerosol surface area. The exception is mixed ammonium sulfate/fulvic acid seed particles, for which a positive correlation is observed $\left(R^{2}=0.82\right)$. A similar trend is observed for the pure fulvic acid seeds, but there are too few data points to draw firm conclusions. The fact that this correlation is significantly tighter than that found for the bulk process on ammonium sulfate/fulvic acid particles suggests that the description of SOA formation on these seed particles might be dominated by a surface process.

Simulation $C$. This evidence for reactive uptake onto ammonium sulfate/fulvic acid surfaces exposed to UV light and $\mathrm{OH}$ radicals has been further explored using the framework in (Eq. 9). Reactive uptake coefficients that reproduce the experimental results are in the range of $0.01<$ $\gamma_{\text {photochem }}<0.03$, with an average $\gamma_{\text {photochem }}=0.016 \pm 0.007$ if SOA is assumed non-hygroscopic. These values are reduced by a factor of 2 for hygroscopic SOA with a range of $0.005<\gamma_{\text {photochem }}<0.012$ and average $\gamma_{\text {photochem }}=0.008 \pm$ 0.003 (Table 6). This is 2-3 times higher than the effective $\gamma$ values reported for urban aerosol (e.g., Volkamer et al., 2007), and about 5-15 times higher than for ammonium sulfate particles in laboratory studies. The apparent agreement in previous studies of $\gamma=3.7 \times 10^{-3}$ (Volkamer et al., 2007), $\gamma>2.3 \times 10^{-3}$ (Liggio et al., 2005a) and $\gamma>10^{-3}$ (Schweitzer et al., 1998) might have been fortuitous (Volkamer et al., 2007). Previous experimentally derived reactive uptake coefficients have been determined under dark conditions (Schweitzer et al., 1998; Liggio et al., 2005b) and, thus, the higher $\gamma_{\text {photochem }}$ as derived here might be due to photoinduced effects. In addition, the observed mass increase in the photochemical experiments is likely a combination of both bulk and surface processes and the values derived as $k_{\text {photochem }}$ and $\gamma_{\text {photochem }}$ should be considered upper limit estimates. However, based on the current data set, it is not possible to isolate the contributions of the individual surfaceand bulk controlled processes.

The experiments of Volkamer et al. (2009) were performed with gas phase $\mathrm{OH}$ concentrations on the order of $10^{7}-$ $10^{8} \mathrm{~cm}^{-3}$; no apparent dependence on the $\mathrm{OH}$ concentration was observed over this range. This suggests that at the upper end of atmospheric $\mathrm{OH}$ concentrations, the glyoxal uptake does not appear to be limited by $\mathrm{OH}$ radicals. However, it seems unlikely that photochemical SOA formation would not depend on light intensity/radical concentration at all. In lack of more detailed data, it is suggested that $k_{\text {photochem }}$ and $\gamma_{\text {photochem }}$ be scaled for atmospheric model applications in a way that $k_{\text {photochem }}=0$ and $\gamma_{\text {photochem }}=0$ at no (or weak) photochemical activity; and the constants in Table 6 should be only used at the highest photochemical activity ([OH] $\sim 10^{7} \mathrm{~cm}^{-3}$ ).
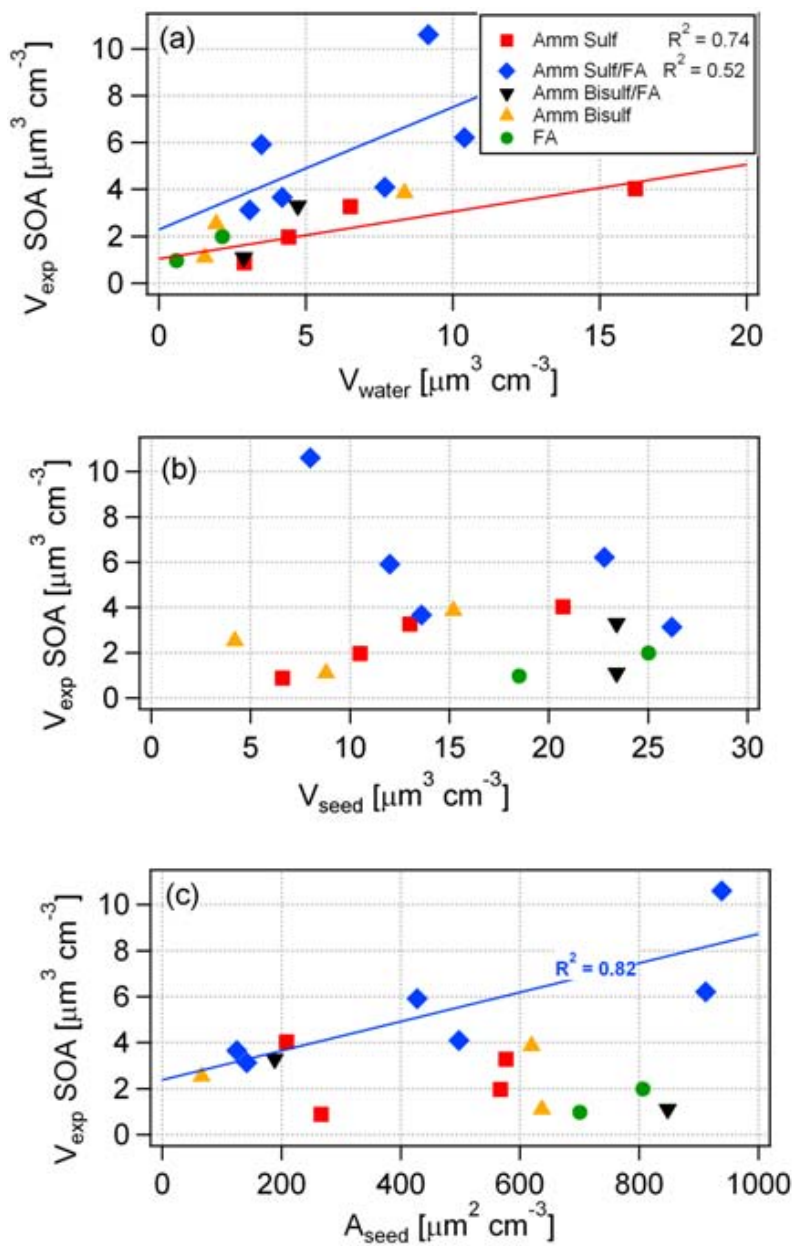

Fig. 5. Observed SOA volumes in the experiments by Volkamer et al. (2009) as a function of (a) water mass associated with seed aerosol; (b) total seed mass (water + seed); (c) total seed surface. The lines depict linear correlations for ammonium sulfate and ammonium sulfate/fulvic acid particles.

\subsubsection{Glyoxal reaction with the ammonium ion}

In addition to products from the self-reaction of glyoxal, AMS spectra have revealed organic nitrogen products (imidazoles) upon reaction of $\mathrm{NH}_{4}+$ ions and glyoxal (Galloway et al., 2009; Noziere et al., 2009a). The formation of such compounds has been confirmed in experiments with different ammonium salts, together with the formation of an iminium intermediate and possibly the formation of heterocycles with C-N and/or C-O bonds (Noziere et al., 2009a). In the same study, a pathway has been suggested where $\mathrm{NH}_{4}{ }^{+}$acts as a catalyst that promotes protonation of the carbonyl group with subsequent $\mathrm{C}-\mathrm{O}$ bond or oligomer formation. In addition to this pathway where $\mathrm{NH}_{4}{ }^{+}$acts as a Bronsted acid, the formation of iminium intermediates leading finally to the formation of stable C-N bonds have been observed. This pathway is highly $\mathrm{pH}$ dependent but only contributes to a small extent 
to SOA formation compared to oligomerization. An empirical expression of an overall second-order rate constant for the reaction of glyoxal with ammonium as a function of $\mathrm{pH}$ and ammonium activity $\left(a_{\mathrm{NH}_{4}}\right)$ reveals strong $\mathrm{pH}$ and concentration dependence (Reaction R8, Table 2) (Noziere et al., 2009a).

\subsubsection{Glyoxal reactions with amines and aminoacids}

In solutions of methylamine (De Haan et al., 2009c) and amino acids (glycine, serine and arginine, De Haan et al., 2009a), SOA formation from glyoxal has been observed to yield imidazoles and oligomers in agreement with ammonium salt experiments but also light-absorbing melanoidins. Glycine and serine only react in their anion form, and thus glyoxal conversion is most efficient at high $\mathrm{pH}$ in agreement with the trends observed in the ammonium catalyzed oligomer formation. The rate constant is similar to that of small amino acids (glycine, serine) (Table 2). The reaction between glyoxal and arginine occurs over the whole $\mathrm{pH}$ range. All amino acids and methylamine only react with the monohydrate of glyoxal.

Both amines and amino acids can comprise a few mass percent of the organic fraction of ambient aerosol (Russell, 2003). Amino acids have not been measured in the gas phase; concentrations for amines are reported in the range of $0.3-$ $6 \mathrm{ng} \mathrm{m}^{-3}$ (Gibb et al., 1999). Thus, the amounts of gas phase amino compounds that are converted into SOA upon uptake into the particle phase will be negligible. The reactions with particulate nitrogen compounds should increase SOA mass by "trapping" glyoxal in the particle.

\section{Sensitivity studies of SOA formation under atmospheric conditions}

\subsection{Model description}

The box model that has been used to simulate laboratory experiments (Sect. 3) only included a very limited chemical mechanism and the reaction parameters $(k, \gamma)$ of an "unknown" newly formulated process that was constrained by laboratory results. In this section, all the reaction parameters shown in Fig. 1 (II) and Table 2 are included in a more extended chemistry box model which is applied to evaluate the efficiency and sensitivities of the chemical processes for a set of atmospherically-relevant initial conditions.

The model represents a simplified version of a parcel model that has been used previously to simulate chemical and microphysical processes in clouds (Feingold and Kreidenweis, 2000; Ervens et al., 2004a). It describes the water uptake of aerosol particles $\left(\sim 10 \mathrm{~nm}<D_{\text {dry }}<\sim 2 \mu \mathrm{m}\right)$ at a given RH according to Köhler theory. However, unlike these prior modeling studies, in the current study, particles reach their equilibrium sizes and no dynamical processes accounting for competition for water vapor are considered which might be a suitable approximation for particles exposed to $\mathrm{RH}<100 \%$. For gas phase species other than water vapor $(\mathrm{OH}$, glyoxal $)$, thermodynamic equilibrium is not necessarily reached, depending on their uptake time scales and their loss rates in the aqueous phase. All particles are assumed to be liquid, i.e., in their metastable state above their efflorescence RH. The mass and water content of the particles is assumed to remain constant during the whole simulation, i.e., the contribution of the newly formed SOA mass to water uptake is neglected (cf. Sect. 3.3.1). This assumption is made in order to be able to clearly separate the contributions of the individual processes over the simulation time and to avoid any feedbacks on reaction rates due to varying water content: e.g., the reaction rates described by $k_{\mathrm{NH}_{4}}, k_{\text {amine }}, k_{\text {aminoacid }}$ are dependent on solute concentrations and thus might become less important if the particles grow and become more dilute. This simplification might not hold in the atmosphere; however, the motivation of the current section is to identify key parameters that impact glyoxal-SOA formation in an idealized system.

The rate constant $k_{\text {photochem }}$ is scaled with the $\mathrm{OH}$ concentration following the discussion in Sect. 3.3.1. The photolysis rate of glyoxal and the $\mathrm{OH}$ concentration are timedependent as a function of the zenith angle. The $\mathrm{OH}$ concentration varies between $\sim 10^{4} \mathrm{~cm}^{-3}$ and $6 \times 10^{6} \mathrm{~cm}^{-3}$ over the course of the day $([\mathrm{OH}]=0$ at night).The uptake of gases (glyoxal, $\mathrm{OH}$ ) into the aqueous particles is described by the same kinetic approach as used for cloud droplets (Eq. 6 and Eq. 7, Table 2) (Ervens et al., 2004a, 2008) using mass accommodation coefficients $\alpha$, Henry's law constants $K_{\mathrm{H}}$ and gas phase diffusion coefficients $D_{\mathrm{g}}$. Due to the lack of appropriate data for uptake into highly concentrated solutions, the same uptake parameters as on pure water surfaces are applied (Table 2). This assumption might lead to an underestimate of the uptake rate into particles as it has been shown that the reactive uptake parameters $\gamma$ usually increase with ionic strength (Schweitzer et al., 1998; Davidovits, 2006). However since $\alpha$ only encompasses the physical process of trace gas accommodation on the surface and $\gamma$ also includes the chemical loss of the respective trace gas in the particle phase, the contribution of an increased $\alpha$ to the enhanced reactive uptake parameter $\gamma$ cannot be evaluated.

\subsection{Model simulations}

\subsubsection{Initial conditions}

Four different sets of model simulations have been performed in order to explore the relative importance of all chemical processes included in Fig. 1 (II) for SOA formation: The base case scenario consists of particles that are composed of ammonium sulfate ( $98 \%$ by mass), internally mixed with methylamine $(1 \%)$ and amino acid $(1 \%)$, and a total dry mass loading of $5 \mu \mathrm{g} \mathrm{m}^{-3}$. For further simulations the role of (i) aerosol loading, (ii) seed composition, (iii) surface- vs. volume-controlled process, (iv) relative humidity, (v) effects 
Table 7. Input parameters for the box model used to evaluate SOA formation from glyoxal under atmospheric conditions. These model simulations include all reaction parameters in Table 2; results are shown in Fig. 6.

\begin{tabular}{lllll}
\hline Simulation & $\begin{array}{l}\text { Mass } \\
\text { loading }\end{array}$ & Aerosol composition & RH & \\
\hline I & $5 \mu \mathrm{g} \mathrm{m}^{-3}$ & Ammonium sulfate & $75 \%$ & base case (photochemistry) \\
IIa & $1 \mu \mathrm{g} \mathrm{m}^{-3}$ & Ammonium sulfate & $75 \%$ & \\
IIb & $10 \mu \mathrm{g} \mathrm{m}^{-3}$ & Ammonium sulfate & $75 \%$ & \\
IIIa & $5 \mu \mathrm{g} \mathrm{m}^{-3}$ & Fulvic Acid & $75 \%$ & \\
IIIb & $5 \mu \mathrm{g} \mathrm{m}^{-3}$ & Ammonium bisulfate & $75 \%$ & \\
IIIc & $5 \mu \mathrm{g} \mathrm{m}^{-3}$ & Ammonium sulfate/Fulvic acid & $75 \%$ & \\
IV & $5 \mu \mathrm{g} \mathrm{m}^{-3}$ & Ammonium sulfate & $75 \%$ & Photochemical processes parameterized by $\gamma_{\text {photochem }}$ \\
Va & $5 \mu \mathrm{g} \mathrm{m}^{-3}$ & Ammonium sulfate & $30 \%$ & \\
Vb & $5 \mu \mathrm{g} \mathrm{m}^{-3}$ & Ammonium sulfate & $50 \%$ & \\
Vc & $5 \mu \mathrm{g} \mathrm{m}^{-3}$ & Ammonium sulfate & $90 \%$ & \\
\hline Only dark processes $\left(k_{\mathrm{photochem}}=0 ; \gamma_{\text {photochem }}=0\right)$ & & \\
\hline VI & $5 \mu \mathrm{g} \mathrm{m}^{-3}$ & Ammonium sulfate & $75 \%$ & base case $($ dark $)$ \\
VIIa & $5 \mu \mathrm{g} \mathrm{m}^{-3}$ & Ammonium sulfate & $75 \%$ & pH $=2$ \\
VIIb & $5 \mu \mathrm{g} \mathrm{m}^{-3}$ & Ammonium sulfate & $75 \%$ & pH $=4$ \\
VIIc & $5 \mu \mathrm{g} \mathrm{m}^{-3}$ & Ammonium sulfate & $75 \%$ & pH $=7$ \\
VIIIa & $5 \mu \mathrm{g} \mathrm{m}^{-3}$ & Ammonium sulfate & $75 \%$ & $k_{\text {hydr1 }}=k(\mathrm{R} 1 \mathrm{~b}), k_{\text {hydr1 }}^{\prime}=k^{\prime}(\mathrm{R} 1 \mathrm{~b})$ \\
& & & & $k$ hydr2 $=k(\mathrm{R} 1 \mathrm{~b}), k_{\text {hydr1 }}^{\prime}=k^{\prime}(\mathrm{R} 1 \mathrm{~b})$ \\
VIIIb & $5 \mu \mathrm{g} \mathrm{m}^{-3}$ & Ammonium sulfate & $75 \%$ & Instantaneous equilbrium \\
\hline
\end{tabular}

of photochemistry vs. night time chemistry, (vi) particle $\mathrm{pH}$, (vii) time scales of hydration kinetics are explored. The conditions for these model runs are summarized in Table 7.

The simulations are performed over twelve hours, starting at 06:00 a.m. or 06:00 p.m., to simulate day or night time chemistry, respectively. In a first set of simulations, a constant glyoxal concentration is assumed (300 ppt) in order to explore sensitivities of SOA formation to a variety of parameters. This concentration is at the lower end of urban conditions, as observed in Mexico City (Volkamer et al., 2006). In a second set of simulations, the impact of particle phase chemistry on glyoxal life time is explored by assuming a closed system that includes gas phase losses by photolysis and $\mathrm{OH}$ reaction $k_{\mathrm{OH}}$ (gas), in addition to particle chemistry (Sect. 4.2.3).

\subsubsection{SOA formation with constant glyoxal concentration}

In Fig. 6, predicted SOA masses are shown as a function of various parameters (Table 7). The reaction volume changes with increasing amount of hygroscopic aerosol mass, and thus the amount of SOA that can be formed in the particles increases proportionally with the amount of aerosol water (Fig. 6a). The fact that the increase in SOA is indeed linear with increase in seed and water mass confirms that there is no limitation in the glyoxal uptake kinetics which is in agreement with the findings in Fig. 3 for low glyoxal concentrations as atmospherically-relevant. Additional model simulations were performed with the same total mass, distributed over different size distributions (not shown). The predicted SOA mass did not significantly vary as compared to the results in all panels in Fig. 6.

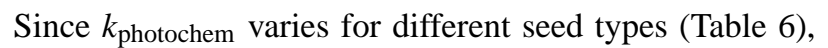
the amount of predicted SOA is a function of the aerosol chemical composition (Fig. 6b). The comparison between the efficiency of an inferred bulk process $\left(k_{\text {photochem }}\right)$ and surface process ( $\left.\gamma_{\text {photochem }}\right)$ yields very similar SOA masses (Fig. 6c). This result crucially depends on the size distribution and its surface/volume ratio. Comparison of Fig. 6b and d, the sensitivity of SOA to RH, reveals that the sensitivity towards chemical composition of the seed aerosol is greater than that caused by variation in RH due to the relative impacts of the aerosol amount/hygroscopicity and $\mathrm{RH}$ to aerosol LWC. The distinct increase in predicted SOA mass at $\mathrm{RH} \sim 75 \%$ is due to the exponential increase in liquid water. This trend is in agreement with laboratory evidence that suggests slightly higher uptake at $\mathrm{RH}>80 \%$ (Figs. 3 and 7 in Volkamer et al., 2009), and field measurements of water-soluble organics in particles that have shown enhanced partitioning above RH 75\% (Hennigan et al., 2009). The major fraction of predicted SOA is comprised of products that are formed through the photochemical pathway $k_{\text {photochem (Sect. 3.3.1.) At low RH, the reaction of glyoxal }}$ 

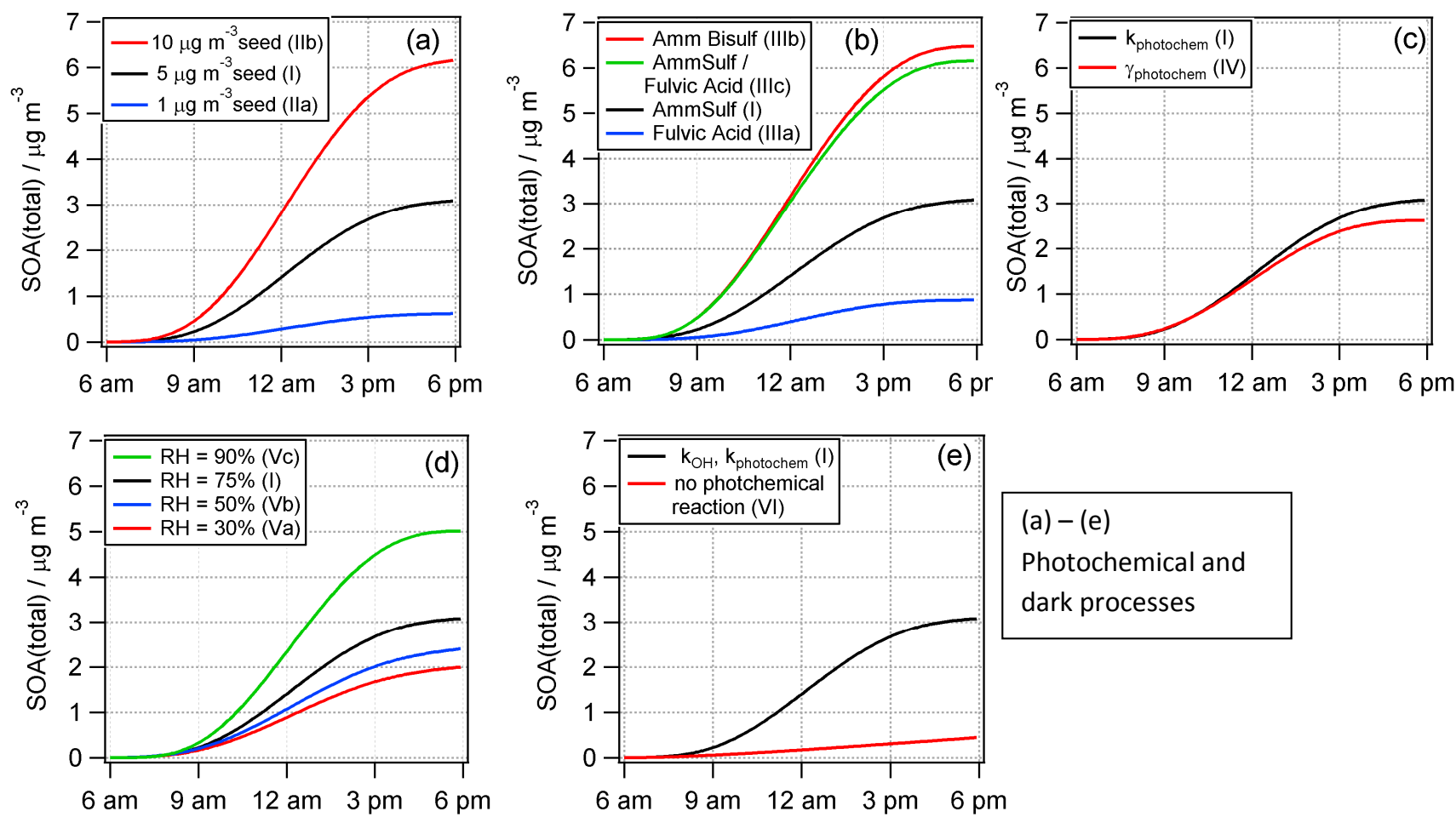
(a) $-(e)$
Photochemical and
dark processes
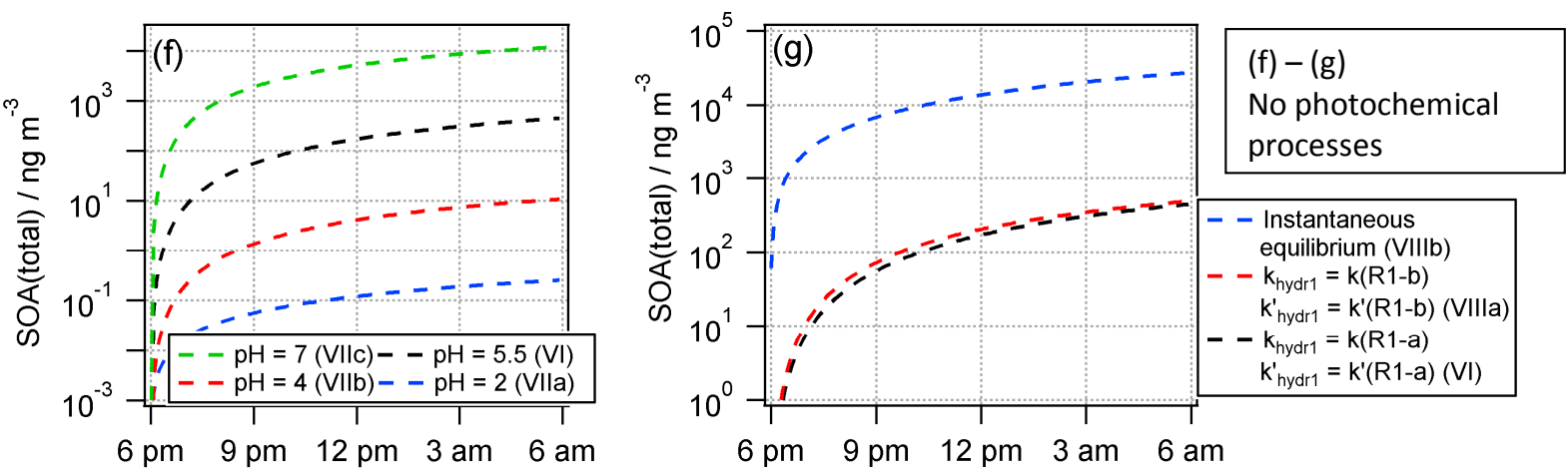

Fig. 6. Predicted SOA masses over a simulation time of $12 \mathrm{~h}$ for the conditions in Table 7 . The model to predict SOA masses $(\mathbf{a}-\mathbf{e})\left[\mu \mathrm{g} \mathrm{m}^{-3}\right.$ ]; (f, $\mathbf{g})\left[\mathrm{ng} \mathrm{m}^{-3}\right]$ includes all processes in Table 2. The black line depicts the base case (solid line: including photochemical processes; dashed line: only dark processes). Dependence of predicted SOA masses from glyoxal (300 ppt; constant over the simulation time) on (a) seed mass, (b) aerosol composition, (c) bulk vs surface process, (d) relative humidity, (e) day/night time chemistry, (f) pH; note that the assumption of $\mathrm{pH}=7$ in the empirical equation (Reaction R8, Table 2) leads to unrealistically high predicted SOA masses. (g) assumptions on hydration kinetics (rate constants: cf Table 2); note that the assumption of instantaneous hydration equilibrium leads to unrealistically high predicted SOA masses. The results in (f) and (g) explore only SOA formation during night time and are shown on a logarithmic scale.

with ammonium (Reaction R8, Table 2) gains in importance due to the increasing ammonium activity. While at $\mathrm{RH} \geq$ $50 \%$, the ammonium reaction contributes about $10 \%$ to the total predicted SOA mass, at $\mathrm{RH}=30 \%$ its contribution is $\sim 30 \%$. The contribution of the $\mathrm{OH}$ reaction is $<1 \%$ of the total predicted SOA mass.

In Fig. 6e, SOA formation from glyoxal over twelve hours during day and night time is compared. For the night-time chemistry, photochemical processes (Reactions R5 and R6, Table 2) are not included in the simulations. (Small amounts of $\mathrm{OH}$ and related radicals during night time are ignored here.) The predicted SOA mass is reduced by a factor of six compared to day time chemistry. Considering the fact that glyoxal concentrations are usually lower during night time than during the day, these results suggest that SOA formation during the night is relatively even less significant than shown in Fig. 6e. However, the identification of products of specific reactions (e.g., imidazoles, melanoidins) as tracers in ambient aerosol particles might be useful to understand sources of SOA mass.

In Fig. 6f and g, the sensitivity of SOA formation without consideration of $k_{\text {photochem }}$ and $k_{\mathrm{OH}}$ is explored. The exponential $\mathrm{pH}$ dependence as inferred by the empirical expression of $k_{\mathrm{NH}_{4}}$ (Reaction R8, Table 2) is reflected in 
the predicted SOA masses that differ by five orders of magnitude. Since glycine and serine only react above $\mathrm{pH}$ $\sim 4$, when a considerable amount of the amino acid is present in its dissociated (anion) form, the formation of SOA by this pathway is almost suppressed at low pH (Fig. 6f). A strong sensitivity of predicted SOA masses to the kinetics of hydration is identified (Fig. 6g) since the timedependent concentration of the glyoxal monohydrate is directly linked to all non-photochemical reaction rates (Reactions R3, R8, R9, R10). The time scale to build up sufficiently high glyoxal monohydrate concentrations (Fig. 2) translates into smaller reactions rates as compared to instantaneous equilibrium assumptions. However, in atmospheric multiphase chemistry models, the assumption of a constant ratio of glyoxal and its dihydrate is usually made [Glyoxal unhydrated $]=K_{\text {hydr1 } 1}$ [ [Glyoxal monohydrate $]=K_{\text {hydr } 1}$. $K_{\text {hydr2 } 2} \cdot$ [Glyoxal dihydrate] with $K_{\text {hydr } 1}=350 ; K_{\text {hydr2 }}=207$ (Table 2). As discussed in Sect. 3.1.1 and shown in Fig. 2, the two hydration steps do not occur instantaneously but are associated with time scales of several hours. If instantaneous equilibrium is assumed predicted SOA masses are unrealistically high. The major fraction of SOA is composed of products from the $\mathrm{NH}_{4}{ }^{+}$catalyzed oligomerization as the empirical parameterization of this reaction implies that any form of glyoxal leads to SOA.

In Fig. 7, the contributions of individual reactants to the total SOA masses as predicted from Fig. 6e-g (night-time) are shown. Without photochemical processes, the glyoxal reaction with ammonium dominates the predicted SOA formation. Only at low $\mathrm{pH}(\mathrm{pH}=2)$, reactions with amines and amino acid contribute significantly $(\geq 10 \%)$ to the total predicted SOA $\left(0.5 \mu \mathrm{g} \mathrm{m}^{-3}\right)$. It is obvious that the contributions of the amine and amino acid reactions are directly linked to the amount of these species in the aerosol particles. The amount of ammonium in the model aerosol ( $\sim 35 \%$ by mass) certainly represents an upper limit for atmospheric aerosol. Close to emission sources, the amount of amines and amino acids might be higher by a factor of 3-7, and could reach levels of up to $14-23 \%$ of the ammonium mass (Sorooshian et al., 2008).

\subsubsection{Glyoxal loss rates}

First evidence that glyoxal uptake to aerosols can affect the atmospheric lifetime of glyoxal was presented by Volkamer et al. (2007). In particular, it was found that the effective glyoxal uptake to form SOA can compete with rapid gas phase glyoxal loss from photolysis and oxidation by $\mathrm{OH}$. In order to test whether this finding is compatible with the data set derived in the present study, another set of model simulations was performed that also represent gas-phase losses of glyoxal. In these simulations, a closed system was assumed that does not include any replenishment of the initial gas phase glyoxal concentration as opposed to the simulations for the results shown in Fig. 6 (constant glyoxal con-

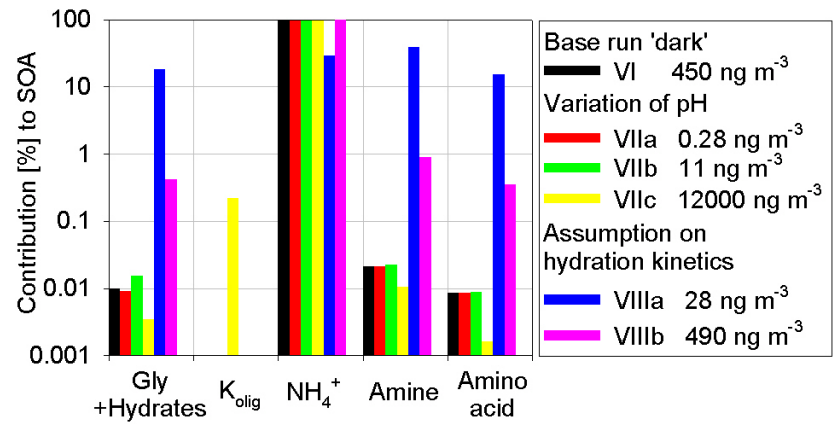

Fig. 7. Percent contributions [\%] to predicted SOA masses by individual processes in absence photochemical activity (night time). The numbers in the legend refer to the model runs as specified in Table 7; the reaction numbers on the $\mathrm{x}$-axis refer to the reactions in Table 2. The masses $\left[\mathrm{ng} \mathrm{m}^{-3}\right]$ denote the absolute predicted SOA masses for the respective runs as shown in Fig. 6.

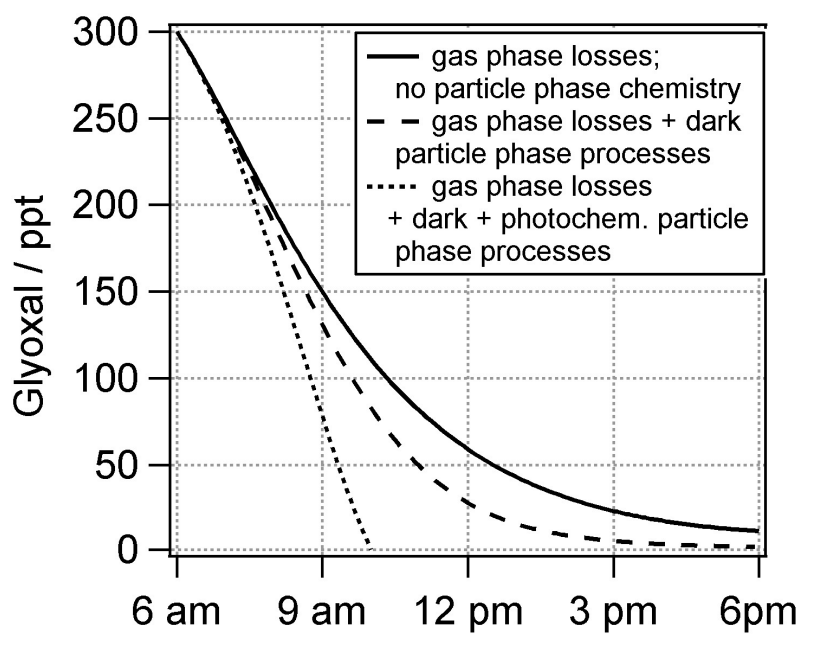

Fig. 8. Concentration profile of glyoxal in the gas phase as a function of time depending on chemical mechanism used (with and without (photochemical) particle phase reactions, respectively).

centration throughout simulation time). If only gas phase losses are considered, the half-life of glyoxal during the day is on the order of two hours for the model conditions chosen here (Fig. 8). This is in good agreement with the glyoxal lifetime that have been calculated on global scale (1.9-2.3 h) (Fu et al., 2008; Myriokefalitakis et al., 2008). If no particle phase chemistry is included in the model, the glyoxal lifetime might be overestimated by a factor of $\sim 6$. It should be noted that the contribution of the particle phase chemistry might also depend on the way how $k_{\text {photochem }}$ is parameterized as a function of light and/or $\mathrm{OH}$ concentration (cf. Sect. 3.3.1). 


\section{Applicability and uncertainties of the developed model framework}

This work presents an empirical extension of a cloud model (Ervens et al., 2003a, 2004a, 2008) to represent glyoxal processing in concentrated aerosol water (see references in Sect. 1). There are underlying assumptions and simplifications associated with this approach: There are no electrostatic interactions of solutes considered here, and all activity coefficients have been assumed as unity, i.e., all rate constants are derived by treating aqueous phase concentrations rather than activities. However, regardless of these simplifications, all rate constants derived and discussed in this study can reproduce observed SOA formation rates from laboratory experiments that have for the most part been conducted on aerosols of realistic atmospheric compositions, e.g., ammonium sulfate, bisulfate, fulvic acid and mixtures of those (Hastings et al., 2005; Kroll et al., 2005; Corrigan et al., 2008; Galloway et al., 2009; Ip et al., 2009; Volkamer et al., 2009). Many of the reactions systems have been investigated for quite different conditions (e.g., aerosol loading, initial glyoxal concentrations, $\mathrm{RH}$ ) and still similar reaction parameters could be derived (Hastings et al., 2005; Liggio et al., 2005a, b; Volkamer et al., 2009). It can be assumed that the parameters derived here are applicable to empirically describe glyoxal losses, with any deviations from ideality being included in these parameters.

It has further been shown that reaction parameters ( $k_{\text {photochem }}, K_{\text {olig }}$ ) depend on the composition of the seed aerosol. Due to the very limited set of experimental studies, no correlation between seed composition and effect on SOA formation rate has been attempted in the present study. As ambient aerosol particles comprise a complex mixture of organic and inorganic compounds, the uncertainty due to different aerosol compositions should be kept in mind if the reaction parameters (Table 2) are applied in atmospheric models. In addition, properties of the formed SOA mass have been assumed $\left(\rho=2 \mathrm{~g} \mathrm{~cm}^{-3}, M=58 \mathrm{~g} \mathrm{~mol}^{-1}\right.$, hygroscopicity $\kappa=0.24$ ) for the conversion of laboratory results into SOA masses and reaction parameters. A smaller density (e.g., as determined for the glyoxal trimer, $\rho \sim 1.69 \mathrm{~g} \mathrm{~cm}^{-3}$ (De Haan et al., 2009b) or higher hygroscopicity $\kappa$ would translate into smaller $k_{\text {photochem. }}$ Thus it is recommended to use the model parameter in combination with the applied SOA properties here in order to derive additional correlations of reactions parameters based on future laboratory experiments, and/or the evaluation of field data (Volkamer et al., 2007).

\section{Summary and conclusions}

Recent laboratory studies of glyoxal uptake and SOA formation on various inorganic and organic seed aerosols have been reviewed and discussed. Based on these studies a consistent data set of empirical reaction parameters that describe glyoxal reactions in aqueous aerosol particles has been compiled. The model approach assumes ideal aqueous solutions, and thus all deviations from non-ideality (activities) in concentrated aqueous particles are lumped into empirical reaction parameters that describe experimental results measured on/in actual aerosol particles:

- Effective Henry's law constants $K_{\mathrm{H}^{*}}{ }^{2} \mathrm{~mol} \mathrm{~kg}_{\mathrm{H}_{2} \mathrm{O}}{ }^{-1}$ $\mathrm{atm}^{-1}$ ] are interpreted in terms of oligomerization upon glyoxal uptake into the aqueous phase. A dimensionless equilibrium constant for the oligomerization $\left(K_{\text {olig }}=1000\right.$, in ammonium sulfate solution $)$ could be derived. Using this constant, kinetic data for the formation and decay of the oligomers could be determined $\left(k_{\text {olig }}=100 \mathrm{M}^{-1} \mathrm{~s}^{-1} ; k_{\text {olig }}^{\prime}=0.1 \mathrm{M}^{-1} \mathrm{~s}^{-1}\right)$. These oligomerization rate constants, and decay rates, together with the rate constants for hydration of glyoxal, are found to reproduce the time resolved formation of SOA in laboratory experiments conducted under dark conditions.

- Observed SOA formation in photochemical laboratory experiments scales linearly with aqueous phase $\mathrm{OH}$ chemistry. However, a cloud chemistry model falls short by a factor 290-870 in explaining SOA amounts formed in aqueous ammonium sulfate and ammonium sulfate/fulvic acid seed assuming hygroscopic SOA (by a larger factor if SOA is assumed to be nonhygroscopic). It is speculated that this difference is due to additional radical recycling and/or photochemical processes that are not captured by the model. A simplified box model that explicitly represents the formation and fate of organic peroxy radicals, $\mathrm{RO}_{2}$, in aqueous solution shows enhanced recombination rates of $\mathrm{RO}_{2}$ in the highly concentrated aqueous particle phase compared to dilute clouds. The additional photochemical process has been parameterized as a first-order process with rate constants of $0.8 \mathrm{~s}^{-1}<k_{\text {photochem }}<7 \mathrm{~s}^{-1}$ depending on the chemical composition of the aqueous seed particle.

- For most seed aerosols, a clear correlation between the mass increase and total water volume in the experiments indicates a SOA formation by a bulk limited process. The only exception is mixed ammonium sulfate/fulvic acid particles which show evidence for surface-controlled uptake. For these experiments, a reactive uptake coefficient $\gamma_{\text {photochem }}=(0.008 \pm 0.003)$ has been determined. The individual contributions of bulk and surface processes could as yet not be determined, and warrant further study.

These processes together with glyoxal reactions with nitrogen-containing reactants (ammonium, methylamine and amino acids) have been included in a chemical box model, and individual pathways for SOA formation have been 
tracked for a wide range of atmospherically relevant conditions. A comparative assessment of different reaction pathways has been conducted:

- Glyoxal can form several $\mu \mathrm{g} \mathrm{m}^{-3}$ SOA mass in twelve hours during day-time (assuming a constant glyoxal concentration of $300 \mathrm{ppt}$ ). This mass is reduced by a factor of six if no photochemical processes occur.

- The chemical composition of the particles (ammonium sulfate, ammonium bisulfate, fulvic acid, amines, and amino acids) affects predicted SOA mass by up to a factor of $\sim 6$ corresponding to the range of the rate constants $k_{\text {photochem }}$, indicating that the sensitivity of glyoxal uptake to chemical composition of aerosols can exceed that of variations in $\mathrm{RH}$.

- For a given chemical composition, the amount of hygroscopic seed aerosol mass scales linearly with the resulting SOA mass due to the proportional increase in water (Volkamer et al., 2009) which is reproduced by the model. Even though the water mass scales with RH, increases in predicted SOA are relatively small over the relevant $\mathrm{RH}$ range since solute-dependent reaction rates (such as $\mathrm{NH}_{4}^{+}$reaction with glyoxal) decrease. Predicted trends of increased SOA formation with increasing RH agree well with field observations (Hennigan et al., 2009).

- Chemical processes in the particle phase can significantly impact the lifetime of gas phase glyoxal (Volkamer et al., 2007). This is reproduced here for the first time by means of a model based on laboratory data. If photochemical particle phase reactions occur, the glyoxal lifetime is reduced by a factor of two; neglecting these processes $\left(k_{\text {photochem }}, \gamma_{\text {photochem }}\right)$, all other particle phase processes reduce glyoxal's lifetime by about $20 \%$ over gas-phase loss processes (photolysis, $\mathrm{OH}$ reaction).

Chemical processes in aqueous particles represent a significant SOA source in addition to the currently considered SOA sources in atmospheric models. The relative SOA amount from this compared to other SOA sources needs to be explored in more comprehensive models. Based on the explorative model studies performed here the following outlook on future studies can be given.

- The widely established paradigm of SOA formation as it is used in most SOA models on regional and global scale is based exclusively on absorptive partitioning of semivolatile products into an organic aerosol phase (Odum et al., 1996; Robinson et al., 2007). While recent advances improve SOA models in terms of mass prediction (Robinson et al., 2007; Dzepina et al., 2009), models have difficulties to reproduce the high oxygen/carbon $(\mathrm{O} / \mathrm{C})$ ratios as measured in the organic fraction of ambient particles (Jimenez et al., 2009; Aiken et al., 2010; Hodzic et al., 2010; Ng et al., 2010). Aqueous phase reactions of glyoxal are a parallel pathway that yields highly oxidized compounds with very high $\mathrm{O} / \mathrm{C}$ ratios $(\geq 1.2)$. For a case study in Mexico City, $10-15 \%$ of the SOA mass could be due to glyoxal (Volkamer et al., 2007), and this SOA source is needed to explain the high measured O/C ratio (Dzepina et al., 2009; Jimenez et al., 2009).

- The sensitivities identified in our model suggest that simple expressions ( $k_{\text {effupt }}$ for dark processes, $k_{\text {photochem }}$ for (the major fraction of) photochemically produced SOA) for this additional SOA source can be developed for use in large-scale model applications. However, the former parameter neglects the reversible character of the oligomer formation, and might lead to an overestimate of SOA formation from this pathway under dark conditions.

The advantage of chemical processes in the bulk aqueous aerosol phase is that the reactor size in which these reactions can occur is determined by the water mass of particles which can be predicted more reliably than the aerosol surface area. However, surface processes do add additional SOA, and the most accurate predictions of SOA from glyoxal will need to also represent additional measures to capture the variability of aerosol surface area on global scales.

- The reaction parameters reveal several key uncertainties in the description of glyoxal processes in aqueous particles that should be addressed in future laboratory studies. These uncertainties include (i) better distinguishing the role of surface and bulk processes in SOA formation, (ii) assess the role of surfactants and acidity, (iii) characterize the fate and re-cycling of radicals in the aqueous phase, and (iv) distinguish the role of radicals and light in photochemical process(es) that dominate SOA formation. The conceptual framework developed here can easily be adopted in comparative studies also of other small water-soluble carbonyl compounds (e.g., methylglyoxal, glycolaldehyde).

\section{Appendix A}

List of rate constants and equilibrium constants used in the current study (Fig. 1), together with the text sections where these parameters are introduced and discussed. The values for all parameters are summarized in Table 2. 
Rate constants

$k_{\text {effupt }} \quad\left[\mathrm{s}^{-1}\right] \quad$ Lumped overall rate constant that includes uptake and oligomer formation in the particle phase under dark conditions; it neglects the back reaction (decay of oligomers) as identified in dark experiments (Sect. 3.1)

$k_{\text {hydr }} \quad\left[\mathrm{M}^{-1} \mathrm{~s}^{-1}\right] \quad$ Hydration rate constant

for an aldehyde (Sect. 2.2)

$k_{\text {hydr }}^{\prime} \quad\left[\mathrm{s}^{-1}\right] \quad$ Decay rate constant of the hydrate of an diol to the aldehyde and water (Sect. 2.2)

$k_{\text {hydr1 }} \quad\left[\mathrm{M}^{-1} \mathrm{~s}^{-1}\right] \quad$ Hydration rate constant for the first hydration step of glyoxal (monohydrate formation) (Sect. 3.2.1)

$k_{\text {hydr1 }}^{\prime} \quad\left[\mathrm{s}^{-1}\right] \quad$ Decay rate constant of glyoxal monohydrate to glyoxal and water (Sect. 3.2.1)

$k_{\text {hydr2 }} \quad\left[\mathrm{M}^{-1} \mathrm{~s}^{-1}\right] \quad$ Hydration rate constant for the second hydration step of glyoxal (dihydrate formation) (Sect. 3.2.1)

$k_{\text {hydr2 }}^{\prime} \quad\left[\mathrm{s}^{-1}\right] \quad$ Decay rate constant of glyoxal dihydrate to glyoxal monohydrate and water (Sect. 3.2.1)

$k_{\text {dimer }} \quad\left[\mathrm{M}^{-1} \mathrm{~s}^{-1}\right] \quad$ Formation rate of glyoxal dimer (Sects. 2.2 and 3.2.2)

$k_{\text {dimer }}^{\prime} \quad\left[\mathrm{M}^{-1} \mathrm{~s}^{-1}\right] \quad$ Decay rate of glyoxal dimer (including elimination of one water molecule) (Sects. 2.2 and 3.2.2)

$k_{\text {olig }} \quad\left[\mathrm{M}^{-1} \mathrm{~s}^{-1}\right] \quad$ Formation rate of oligomers of glyoxal; lumped constant that includes any combination of glyoxal with glyoxal monomers or oligomers (Sect. 3.2.3)

$k_{\text {olig }}^{\prime} \quad\left[\mathrm{M}^{-1} \mathrm{~s}^{-1}\right] \quad$ Decay rate of glyoxal oligomers (including elimination of one water molecule) (Sect. 3.2.3)

$k_{\mathrm{OH}} \quad\left[\mathrm{M}^{-1} \mathrm{~s}^{-1}\right] \quad$ Rate constant of the $\mathrm{OH}$ radical with glyoxal in dilute aqueous solution (Sect. 3.3.1)

$k_{\text {photochem }}\left[\mathrm{s}^{-1}\right] \quad$ Empirical rate constant that has been fit to experimental results to account for "excess SOA" that has been observed in photochemical laboratory experiments and cannot be reproduced by $k_{\mathrm{OH}}$. This rate constant parameterizes additional chemical processes that are initiated by radicals and/or $h v$ and form high-molecular-weight compounds (Sect. 3.3.1, Simulation B, and Table 6)

$\gamma_{\text {photochem dimension }}$ Reactive uptake parameter that less has been obtained by interpreting SOA formation on ammonium sulfate/fulvic acid particles as a surface controlled process. The value likely represents an upper limit as also bulk processes contribute to SOA formation (Sect. 3.3.1, Simulation C, and Table 6).

$k_{\mathrm{NH}_{4}} \quad$ Empirical rate constant $\left(f\left(\mathrm{aNH}_{4}, \mathrm{pH}\right)\right)$ for the aqueous phase reaction of glyoxal with ammonium; $\mathrm{NH}_{4}{ }^{+}$catalyzed oligomer formation (Noziere et al., 2009a) (Sect. 3.3.2)

$k_{\text {amine }}$ phase reaction of glyoxal with monomethyl amine (De Haan et al., 2009c) (Sect. 3.3.3)

$k_{\text {aminoacid }}$

Equilibrium constants

rate constant of the aqueous phase reaction of glyoxal with amino acids (serine, glycine, arginine) (De Haan et al., 2009a) (Sect. 3.3.3)

\begin{tabular}{|c|c|c|}
\hline$K_{\mathrm{H}}$ & {$\left[\mathrm{M} \mathrm{atm}^{-1}\right] \quad \mathrm{F}$} & $\begin{array}{l}\text { Henry's law constant, } \\
\text { physical solubility (Sect. 2.2) }\end{array}$ \\
\hline$K_{\text {Hydr }}$ & & $\begin{array}{l}\text { Hydration equilibrium } \\
\text { constant for an aldehyde (Sect. 2.2) }\end{array}$ \\
\hline$K_{\text {Hydr1 }}$ & & $\begin{array}{l}\text { Hydration equilibrium constant of } \\
\text { glyoxal and its monohydrate } \\
\text { (Sect. 3.2.1) }\end{array}$ \\
\hline$K_{\text {Hydr2 }}$ & & $\begin{array}{l}\text { Hydration equilibrium constant } \\
\text { of glyoxal monohydrate } \\
\text { and dihydrate (Sect. 3.2.1) }\end{array}$ \\
\hline$K_{\text {Heff,hydr }}$ & {$\left[\mathrm{M} \mathrm{atm}^{-1}\right]$} & $\begin{array}{l}\text { Effective Henry's law } \\
\text { constant of glyoxal, enhanced } \\
\text { aqueous phase partitioning due } \\
\text { to hydration (Sects. } 2.2 \text { and } 3.2 .1 \text { ) }\end{array}$ \\
\hline$K_{\text {dimer }}$ & $\begin{array}{l}\text { dimension } \\
\text { less }\end{array}$ & $\begin{array}{l}\text { Equilibrium constant } \\
\text { of glyoxal and its dimer; } \\
\text { elimination of water in } \\
\text { dimerization step (Sect. 3.2.2) }\end{array}$ \\
\hline$K_{\mathrm{H}}^{\text {dimer }}$ & {$\left[\mathrm{M} \mathrm{atm}^{-1}\right]$} & $\begin{array}{l}\text { Effective Henry's law } \\
\text { constant of an aldehyde } \\
\text { (glyoxal), enhanced aqueous } \\
\text { phase partitioning due } \\
\text { to dimerisation (Sect. 2.2) }\end{array}$ \\
\hline$K_{\text {olig }}$ & $\begin{array}{l}\text { dimension } \\
\text { less }\end{array}$ & $\begin{array}{l}\text { Equilibrium constant of } \\
\text { glyoxal and oligomers; } \\
\text { elimination of water in oligomerization } \\
\text { step (Sects. 2.2, 3.2.3 and Table } 3 \text { ) }\end{array}$ \\
\hline$K_{\mathrm{H}}^{*}$ & $\begin{array}{l}{\left[\mathrm{mol} \mathrm{kg}_{\mathrm{H}_{2} \mathrm{O}}-1\right.} \\
\left.\mathrm{atm}^{-1}\right]\end{array}$ & $\begin{array}{l}\text { Effective Henry's law } \\
\text { constant of glyoxal (molal } \\
\text { units) enhanced aqueous phase } \\
\text { partitioning due to oligomerization } \\
\text { (Sect. } 2.2 \text { and Table 3) }\end{array}$ \\
\hline
\end{tabular}

Acknowledgements. We thank D. O. De Haan for helpful discussions. Funding from the Innovative Research Program (Cooperative Institute for Research in Environmental Sciences, University of Colorado, Boulder) is acknowledged. BE acknowledges support from the Office of Science (BER), US Department of Energy, grant DE-FG02-08ER64539. RV acknowledges an NSF-CAREER award AGS-0847793.

Edited by: M. Kanakidou

\section{References}

Aiken, A. C., Salcedo, D., Cubison, M. J., Huffman, J. A., DeCarlo, P. F., Ulbrich, I. M., Docherty, K. S., Sueper, D., Kimmel, J. R., Worsnop, D. R., Trimborn, A., Northway, M., Stone, E. A., Schauer, J. J., Volkamer, R. M., Fortner, E., de Foy, B., Wang, J., Laskin, A., Shutthanandan, V., Zheng, J., Zhang, R., Gaffney, J., Marley, N. A., Paredes-Miranda, G., Arnott, W. P., Molina, L. T., Sosa, G., and Jimenez, J. L.: Mexico City aerosol analysis during MILAGRO using high resolution aerosol mass spectrometry at the urban supersite (T0) - Part 1: Fine particle composition and organic source apportionment, Atmos. Chem. Phys., 9, 66336653, doi:10.5194/acp-9-6633-2009, 2009.

Altieri, K., Carlton, A. G., Lim, H., Turpin, B. J., and Seitzinger, S. P.: Evidence for oligomer formation in clouds: reaction of iso- 
prene oxidation products, Environ. Sci. Technol., 40(16), 49564960, 2006.

Bahreini, R., Ervens, B., Middlebrook, A. M., Warneke, C., DeGouw, J. A., DeCarlo, P., Jimenez, J. L., Brock, C. A., Neuman, J. A., Ryerson, T. B., Stark, H., Atlas, E., Brioude, J., Fried, A., Holloway, J. S., Peischl, J., Richter, D., Walega, J., Weibring, P., Wollny, A. G., and Fehsenfeld, F. C.: Organic aerosol formation in urban and industrial plumes in Houston, TX, J. Geophys. Res., 114, D00F16, doi:10.1029/2008JD011493, 2009.

Bao, L., Matsumoto, M., Kubota, T., Kazuhiko, S., Wang, Q., and Sakamoto, K.: Gas/particle partitioning of low-molecular-weight dicarboxylic acids at a suburban site in Saitama, Japan, Atmos. Environ., in press, 2009.

Barnard, J. C., Volkamer, R., and Kassianov, E. I.: Estimation of the mass absorption cross section of the organic carbon component of aerosols in the Mexico City Metropolitan Area, Atmos. Chem. Phys., 8, 6665-6679, doi:10.5194/acp-8-6665-2008, 2008.

Barsanti, K. C. and Pankow, J. F.: Thermodynamics of the formation of atmospheric organic particulate matter by accretion reactions - Part 2 Dialdehydes, methylglyoxal, and diketones, Atmos. Environ., 39, 6597-6607, 2005.

Betterton, E. A. and Hoffmann, M. R.: Henry's law constants of some environmentally important aldehydes, Environ. Sci. Technol., 22, 1415-1418, 1988.

Bielski, B. H. J., Cabell, D. E., Arudi, R. L., and Ross, A. B.: Reactivity of $\mathrm{HO}_{2} / \mathrm{O}_{2}^{-}$radicals in aqueous solution, J. Phys. Chem. Ref. Data, 14(4), 1041-1100, 1985.

Bloss, C., Wagner, V., Jenkin, M. E., Volkamer, R., Bloss, W. J., Lee, J. D., Heard, D. E., Wirtz, K., Martin-Reviejo, M., Rea, G., Wenger, J. C., and Pilling, M. J.: Development of a detailed chemical mechanism (MCMv3.1) for the atmospheric oxidation of aromatic hydrocarbons, Atmos. Chem. Phys., 5, 641-664, doi:10.5194/acp-5-641-2005, 2005.

Bowman, F. M. and Melton, J. A.: Effect of activity coefficient models on predictions of secondary organic aerosol partitioning, J. Aerosol Sci., 35, 1415-1438, 2004.

Buxton, G. V., Malone, T. N., and Salmon, G. A.: Oxidation of glyoxal initiated by $\mathrm{OH}$ in oxygenated aqueous solutions, J. Chem. Soc. Faraday Trans., 93(16), 2889-2891, 1997.

Carlton, A. G., Turpin, B. J., Altieri, K. E., Reff, A., Seitzinger, S., Lim, H., and Ervens, B.: Atmospheric oxalic acid and SOA production from glyoxal: results of aqueous photooxidation experiments, Atmos. Environ., 41, 7588-7602, 2007.

Chen, J., Griffin, R. J., Grini, A., and Tulet, P.: Modeling secondary organic aerosol formation through cloud processing of organic compounds, Atmos. Chem. Phys., 7, 5343-5355, doi:10.5194/acp-7-5343-2007, 2007.

Christensen, H., Sehested, K., and Corfitzen, H.: Reactions of hydroxyl radicals with hydrogen peroxide at ambient and elevated temperatures, J. Phys. Chem., 86(9), 1588-1590, doi:10.1021/j100206a023, 1982.

Claeys, M., Graham, B., Vas, G., Wang, W., Vermeylen, R., Pashynska, V., Cafmeyer, J., Guyon, P., Andreae, M. O., Artaxo, P., and Maenhaut, W.: Formation of secondary organic aerosols, Science, 303, 1173-1176, 2004.

Clegg, S. L. and Brimblecombe, P.: Thermodynamic model for the system $\mathrm{H}^{+}-\mathrm{NH}_{4}{ }^{+}-\mathrm{Na}^{+}-\mathrm{SO}_{4}^{2-}-\mathrm{NO}_{3}^{-}-\mathrm{Cl}^{-}-\mathrm{H}_{2} \mathrm{O}$ at $298.15 \mathrm{~K}, \mathrm{~J}$. Phys. Chem. A, 102, 2155-2171, 1998.

Corrigan, A. L., Hanley, S. W., and De Haan, D. O.: Uptake of glyoxal by organic and inorganic aerosol, Environ. Sci. Technol., 42(12), 4428-4433, 2008.

Creighton, D. J., Migliorini, M., Pourmotabbed, T., and Guha, M. K.: Optimization of efficieny in the glyoxylase pathway, Biochem., 27, 7376-7384, 1988.

Davidovits, M., Hu, J. H., Worsnop, D. R., Zahniser, M. S., and Kolb, C. E.: Entry of Gas Molecules into Liquids, Faraday Discuss., 100, 65-82, 1995.

Davidovits, P.: Mass accommodation and Chemical Reactions at Gas-Liquid Interfaces, Chem. Reviews, 2006.

De Haan, D. O., Corrigan, A. L., Smith, K. W., Stroik, D. R., Turley, J. J., Lee, F. E., Tolbert, M. A., Jimenez, J. L., Cordova, K. E., and Ferrell, G. R.: Secondary organic aerosol-forming reactions of glyoxal with amino acids, Environ. Sci. Technol., 43(8), 28182824, 2009a.

De Haan, D. O., Corrigan, A. L., Tolbert, M. A., Jimenez, J. L., Wood, S. E., and Turley, J. J.: Secondary Organic Aerosol Formation by Self-Reactions of Methylglyoxal and Glyoxal in Evaporating Droplets, Environ. Sci. Technol., 43(21), 8184-8190, 10.1021/es902152t, 2009b.

De Haan, D. O., Tolbert, M. A., and Jimenez, J. L.: Atmospheric condensed phase reactions of glyoxal with methylamine, Geophys. Res. Lett., 36, L11819, doi:10.1029/2009GL037441, 2009c.

Debus, H.: Über die Einwirkung des Ammoniaks auf Glyoxal, Annalen der Chemie und Pharmacie, doi:10.1002/jlac.18581070209, 107, 199-208, 1858.

DeGouw, J. A., Middlebrook, A. M., Warneke, C., Goldan, P. D., Kuster, W. C., Roberts, J. M., Fehsenfeld, F. C., Worsnop, D. R., Canagaratna, M. R., Pszenny, A. A. P., Keene, W. C., Marchewka, M., Bertram, S. B., and Bates, T. S.: Budget of organic carbon in a polluted atmosphere: results from the New England Air Quality Study in 2002, J. Geophys. Res., 110, D16305, doi:10.1029/2004JD005623, 2005.

Denkenberger, K. A., Moffet, R. C., Holecek, J. C., Robetier, T. P., and Prather, K. A.: Real-time, single-particle measurements of oligomers in aged ambient aerosol particles, Environ. Sci. Technol., 41(15), 5439-5446, 2007.

Dix, B., Barnard, J. C., and Volkamer, R.: Implications of the insitu measured mass absorption cross section of organic aerosols in Mexico City on the atmospheric energy balance, satellite retrievals, and photochemistry, Proceedings of the International Radiation Symposium (IRS2008), Foz do Iguaçu, Brazil, 2008.

Dzepina, K., Volkamer, R. M., Madronich, S., Tulet, P., Ulbrich, I. M., Zhang, Q., Cappa, C. D., Ziemann, P. J., and Jimenez, J. L.: Evaluation of recently-proposed secondary organic aerosol models for a case study in Mexico City, Atmos. Chem. Phys., 9, 5681-5709, doi:10.5194/acp-9-5681-2009, 2009.

Elliot, A. J. and Buxton, G. V.: Temperature dependence of the reactions $\mathrm{OH}+\mathrm{O}_{2}^{-}$and $\mathrm{OH}+\mathrm{HO}_{2}$ in water up to $200^{\circ} \mathrm{C}$, J. Chem. Soc. Faraday Trans., 88, 2465-2470, 1992.

Ervens, B., George, C., Williams, J. E., Buxton, G. V., Salmon, G. A., Bydder, M., Wilkinson, F., Dentener, F., Mirabel, P., Wolke, R., and Herrmann, H.: CAPRAM2.4 (MODAC mechanism): An extended and condensed tropospheric aqueous phase mechanism and its application, J. Geophys. Res., 108(D14), 4426, doi:10.1029/2002JD002202, 2003a.

Ervens, B., Gligorovski, S., and Herrmann, H.: Temperature dependent rate constants for hydroxyl radical reactions with organic 
compounds in aqueous solution, Phys. Chem. Chem. Phys., 5, 1811-1824, 2003b.

Ervens, B., Feingold, G., Frost, G. J., and Kreidenweis, S. M.: A modeling study of aqueous production of dicarboxylic acids, 1. Chemical pathways and speciated organic mass production, J. Geophys. Res., 109, D15205, doi:10.1029/2003JD004387, 2004a.

Ervens, B., Feingold, G., Clegg, S. L., and Kreidenweis, S. M.: A modeling study of aqueous production of dicarboxylic acids, 2. Implications for cloud microphysics, J. Geophys. Res., 109, D15206, doi:10.1029/2004JD004575, 2004b.

Ervens, B., Carlton, A. G., Turpin, B. J., Altieri, K. E., Kreidenweis, S. M., and Feingold, G.: Secondary organic aerosol yields from cloud-processing of isoprene oxidation products, Geophys. Res. Lett., 35, L02816, doi:10.1029/2007GL031828, 2008.

Ervens, B., Cubison, M. J., Andrews, E., Feingold, G., Ogren, J. A., Jimenez, J. L., Quinn, P. K., Bates, T. S., Wang, J., Zhang, Q., Coe, H., Flynn, M., and Allan, J. D.: CCN predictions using simplified assumptions of organic aerosol composition and mixing state: a synthesis from six different locations, Atmos. Chem. Phys., 10, 4795-4807, doi:10.5194/acp-10-4795-2010, 2010.

Feingold, G. and Kreidenweis, S.: Does cloud processing of aerosol enhance droplet concentrations?, J. Geophys. Res., 105(D19), 24351-24361, 2000.

Fratzke, A. R. and Reilly, P. J.: Thermodynamic and kinetic analysis of the dimerization of aqueous glyoxal, Int. J. Chem. Kinet., 18, 775-789, 1986.

Fu, T., Jacob, D. J., Wittrock, F., Burrows, J. P., Vrekoussis, M., and Henze, D. K.: Global budgets of atmospheric glyoxal, methylglyoxal, and implications for formation of secondary organic aerosol, J. Geophys. Res., 113, D15303, doi:10.1029/2007JD009505, 2008.

$\mathrm{Fu}, \mathrm{T}$., Jacob, D. J., and Heald, C. L.: Aqueous-phase reactive uptake of dicarbonyls as a source of organic aerosol over eastern North America, Atmos. Environ., 43, 1814-1822, 2009.

Galloway, M. M., Chhabra, P. S., Chan, A. W. H., Surratt, J. D., Flagan, R. C., Seinfeld, J. H., and Keutsch, F. N.: Glyoxal uptake on ammonium sulphate seed aerosol: reaction products and reversibility of uptake under dark and irradiated conditions, Atmos. Chem. Phys., 9, 3331-3345, doi:10.5194/acp-9-3331-2009, 2009

Gao, S., Keywood, M., Ng, N. L., Surratt, J., Varutbangkul, V., Bahreini, R., Flagan, R. C., and Seinfeld, J. H.: Low-molecularweight and oligomeric components in secondary organic aerosols from the ozonolysis of cycloalkenes and $\alpha$-pinene, J. Phys. Chem. A, 108(46), doi:10.1021/jp047466e, 2004.

Gelencser, A.: Carbonaceous Aerosol, Atmospheric and Oceanographic Sciences Library, edited by: Mysak, L. A., and Hamilton, K., Springer, Dordrecht (NL), 350 pp., 2004.

Gibb, S. W., Mantoura, R. F. C., and Liss, P. S.: Ocean-atmosphere exchange and atmospheric speciation of ammonia and methylamines in the region of the NW Arabian Sea, Global Biochem. Cy., 13(1), 161-178, 1999.

Gomez-Gonzalez, Y., Surratt, J. D., Cuyckens, F., Szmigielski, R., Vermeylen, R., Jaoui, M., Lewandowski, M., Offenberg, J. H., Kleindienst, T. E., Edney, E. O., Blockhuys, F., VanAlsenoy, C., Maenhaut, W., and Claeys, M.: Characterization of organosulfates from the photooxidation of isoprene and unsaturated fatty acids in ambient aerosol using liquid chromatography/(-) elec- trospray ionization mass spectrometry, J. Mass. Spectrom., 43, 371-382, 2008.

Griffin, R. J., Cocker, D. R., Flagan, R. C., and Seinfeld, J. H.: Organic aerosol formation from the oxidation of biogenic hydrocarbon, J. Geophys. Res., 104, D3, 3555-3567, 1999.

Griffin, R. J., Dabdub, D., and Seinfeld, J. H.: Development and initial evaluation of a dynamic species-resolved model for gas phase chemistry and size-resolved gas/particle partitioning associated with secondary organic aerosol formation, J. Geophys Res., 110, D05304, doi:10.1029/2004JD005219, 2005.

Hanson, D., Burkholder, J. B., Howard, C. J., and Ravishankara, A. R.: Measurement of $\mathrm{OH}$ and $\mathrm{HO}_{2}$ Radical Uptake Coefficients on Water and Sulfuric Acid Surfaces, J. Phys. Chem., 96, 49794985, 1992.

Hastings, W. P., Koehler, C. A., Bailey, E. L., and De Haan, D. O.: Secondary organic aerosol formation by glyoxal hydration and oligomer formation: humidity effects and equilibrium shifts during analysis, Environ. Sci. Technol., 39(22), 8728-8735, 2005.

Hennigan, C. J., Bergin, M. H., Russell, A. G., Nenes, A., and Weber, R. J.: Gas/particle partitioning of water-soluble organic aerosol in Atlanta, Atmos. Chem. Phys., 9, 3613-3628, doi:10.5194/acp-9-3613-2009, 2009.

Herrmann, H.: Kinetics of aqueous phase reactions relevant for atmospheric chemistry, Chem. Reviews, 103(12), 4691-4716, 2003.

Hodzic, A., Jimenez, J. L., Madronich, S., Canagaratna, M. R., DeCarlo, P. F., Kleinman, L., and Fast, J.: Modeling organic aerosols in a megacity: potential contribution of semi-volatile and intermediate volatility primary organic compounds to secondary organic aerosol formation, Atmos. Chem. Phys., 10, 5491-5514, doi:10.5194/acp-10-5491-2010, 2010.

Igawa, M., Munger, J. W., and Hoffmann, M. R.: Analysis of aldehydes in cloud- and fogwater samples by HPLC with a postcolumn reaction detector, Environ. Sci. Technol., 23, 556-561, 1989.

Ip, H. S. S., Huang, X. H. H., and Yu, J. Z.: Effective Henry's law constants of glyoxal, glyoxylic acid and glycolic acid, Geophys Res. Lett., 36, L01802, doi:10.1029/2008GL036212, 2009.

Jimenez, J. L., Canagaratna, M. R., Donahue, N. M., Prevot, A. S. H., Zhang, Q., Kroll, J. H., DeCarlo, P. F., Allan, J. D., Coe, H., Ng, N. L., Aiken, A. C., Docherty, K. S., Ulbrich, I. M., Grieshop, A. P., Robinson, A. L., Duplissy, J., Smith, J. D., Wilson, K. R., Lanz, V. A., Hueglin, C., Sun, Y. L., Tian, J., Laaksonen, A., Raatikainen, T., Rautiainen, J., Vaattovaara, P., Ehn, M., Kulmala, M., Tomlinson, J. M., Collins, D. R., Cubison, M. J., Dunlea, E. J., Huffman, J. A., Onasch, T. B., Alfarra, M. R., Williams, P. I., Bower, K., Kondo, Y., Schneider, J., Drewnick, F., Borrmann, S., Weimer, S., Demerjian, K., Salcedo, D., Cottrell, L., Griffin, R., Takami, A., Miyoshi, T., Hatakeyama, S., Shimono, A., Sun, J. Y., Zhang, Y. M., Dzepina, K., Kimmel, J. R., Sueper, D., Jayne, J. T., Herndon, S. C., Trimborn, A. M., Williams, L. R., Wood, E. C., Middlebrook, A. M., Kolb, C. E., Baltensperger, U., and Worsnop, D. R.: Evolution of organic aerosols in the atmosphere, Science, 326, 5959, 15251529, doi:10.1126/science.1180353, 2009.

Karpel vel Leitner, N. and Doré, M.: Mecanisme d'action des Radicaux $\mathrm{OH}$ sur les Acides glycolique, glyoxylique, acetique et oxalique en solution aqueouse: Incidence sur la consammation de peroxyde d'hydrogene dans les systeme $\mathrm{H}_{2} \mathrm{O}_{2} / \mathrm{UV}$ et $\mathrm{O}_{3} / \mathrm{H}_{2} \mathrm{O}_{2}$, 
Wat. Res. , 6, 1383-1397, 1997.

Kläning, U. K., Sehested, K., and Holcman, J.: Standard Gibbs energy of formation of the hydroxyl radical in aqueous solution. Rate constants for the reaction $\mathrm{ClO}_{2}^{-}+\mathrm{O}_{3}=\mathrm{O}_{3}^{-}+\mathrm{ClO}_{2}$, J. Phys. Chem., 89, 760-763, 1985.

Kleinman, L. I., Springston, S. R., Wang, J., Daum, P. H., Lee, Y.-N., Nunnermacker, L. J., Senum, G. I., Weinstein-Lloyd, J., Alexander, M. L., Hubbe, J., Ortega, J., Zaveri, R. A., Canagaratna, M. R., and Jayne, J.: The time evolution of aerosol size distribution over the Mexico City plateau, Atmos. Chem. Phys., 9, 4261-4278, doi:10.5194/acp-9-4261-2009, 2009.

Kroll, J. H., Ng, N. L., Murphy, S. M., Varutbangkul, V., Flagan, R. C., and Seinfeld, J. H.: Chamber studies of secondary organic aerosol growth by reactive uptake of simple carbonyl compounds, J. Geophys. Res., 110, D23207, doi:10.1029/2005JD006004, 2005.

Kua, J., Hanley, S. W., and De Haan, D. O.: Thermodynamics and kinetics of glyoxal dimer formation: a computational study, J. Phys. Chem. A, 112(1), 66-72, 2008.

Lide, D. R. (ed.): CRC Handbook of Chemistry and Physics, 89th ed., CRC Press/Taylor and Francis, Boca Raton, FL, 2009.

Liggio, J., Li, S.-M., and McLaren, R.: Reactive uptake of glyoxal by particulate matter, J. Geophys. Res. , 110, D10304, doi:10.1029/2004JD005113, 2005a.

Liggio, J., Li, S.-M., and McLaren, R.: Heterogeneous reactions of glyoxal on particulate matter: identification of acetals and sulfate esters, Environ. Sci. Technol., 39, 1532-1541, 2005 b.

Lim, H., Carlton, A. G., and Turpin, B. J.: Isoprene forms secondary organic aerosol in Atlanta: results from time-resolved measurements during the Atlanta supersite experiment, Environ. Sci. Technol., 39, 4441-4446, 2005.

Lim, Y. B., Tan, Y., Perri, M. J., Seitzinger, S. P., and Turpin, B. $\mathrm{J} .:$ Aqueous chemistry and its role in secondary organic aerosol (SOA) formation, Atmos. Chem. Phys. Discuss., 10, 1416114207, doi:10.5194/acpd-10-14161-2010, 2010.

Limbeck, A. and Puxbaum, H.: Dependence of in-cloud scavenging of polar organic aerosol compounds on the water solubility, J. Geophys. Res., 105(D15), 19857-19867, 2000.

Lind, J. A. and Kok, G. L.: Correction to "Henry's law Determinations for aqueous solutions of hydrogen peroxide, methylhydroperoxide and peroxyacetic acid" by John A. Lind and Gregory L. Kok, J. Geophys. Res. , 99, D10, 21119 pp., 1994.

Loeffler, K. W., Koehler, C. A., Paul, N. M., and De Haan, D. O.: Oligomer formation in evaporating aqueous glyoxal and methylglyoxal solutions, Environ. Sci. Technol., 40(20), 6318-6323, 2006.

Martin-Reviejo, M. and Wirtz, K.: Is benzene a precursor for secondary organic aerosol?, Environ. Sci. Technol., 39(4), 10451054, 2005.

Matsunaga, S., Mochida, M., and Kawamura, K.: Variation of the atmospheric concentrations of biogenic carbonyl compounds and their removal processes in the northern forest at Moshiri, Hokkaido Island in Japan, J. Geophys. Res., 109, D04302, doi:10.1029/2003JD004100, 2004.

Matsunaga, S. N., Kato, S., Yoshino, A., Greenberg, J. P., Kajii, Y., and Guenther, A. B.: Gas-aerosol partitioning of semi volatile carbonyls in polluted atmosphere in Hachioji, Tokyo, Geophys. Res. Lett., 32(11), L11805, doi:10.1029/2004g1021893, 2005.

McElroy, W. J.: The interactions of gases with aqueous aerosol par- ticles, Central Electr., Gen. Board, Part IV, 1997.

Myriokefalitakis, S., Vrekoussis, M., Tsigaridis, K., Wittrock, F., Richter, A., Brühl, C., Volkamer, R., Burrows, J. P., and Kanakidou, M.: The influence of natural and anthropogenic secondary sources on the glyoxal global distribution, Atmos. Chem. Phys., 8, 4965-4981, doi:10.5194/acp-8-4965-2008, 2008.

Neta, P., Huie, R. E., and Ross, A. B.: Rate constants for reactions of peroxyl radicals in fluid solutions, J. Phys. Chem. Ref. Data, 19(2), 413-513, 1990.

Ng, N. L., Kroll, J. H., Chan, A. W. H., Chhabra, P. S., Flagan, R. C., and Seinfeld, J. H.: Secondary organic aerosol formation from m-xylene, toluene, and benzene, Atmos. Chem. Phys., 7, 3909-3922, doi:10.5194/acp-7-3909-2007, 2007.

Ng, N. L., Canagaratna, M. R., Zhang, Q., Jimenez, J. L., Tian, J., Ulbrich, I. M., Kroll, J. H., Docherty, K. S., Chhabra, P. S., Bahreini, R., Murphy, S. M., Seinfeld, J. H., Hildebrandt, L., Donahue, N. M., DeCarlo, P. F., Lanz, V. A., Prévôt, A. S. H., Dinar, E., Rudich, Y., and Worsnop, D. R.: Organic aerosol components observed in Northern Hemispheric datasets from Aerosol Mass Spectrometry, Atmos. Chem. Phys., 10, 46254641, doi:10.5194/acp-10-4625-2010, 2010.

Noziere, B., Dziedzic, P., and Cordova, A.: Products and kinetics of the liquid-phase reaction of glyoxal catalysed by ammonium ions $\left(\mathrm{NH}_{4}^{+}\right)$, J. Phys. Chem. A, 113, 231-237, 2009 a.

Nozière, B., Dziedzic, P., and Córdova, A.: Common inorganic ions are efficient catalysts for organic reactions in atmospheric aerosols and other natural environments, Atmos. Chem. Phys. Discuss., 9, 1-21, doi:10.5194/acpd-9-1-2009, 2009b.

Nozière, B., Ekström, S., Alsberg, T., and Holmström, S.: Radical-initiated formation of organosulfates and surfactants in atmospheric aerosols, Geophys. Res. Lett., 37(5), L05806, doi:10.1029/2009g1041683, 2010.

Odum, J. R., Hoffmann, T., Bowman, F., Collins, D., Flagan, R. C., and Seinfeld, J. H.: Gas/particle partitioning and secondary organic aerosol yields, Environ. Sci. Technol., 30, 2580-2585, 1996.

Pankow, J. F.: An absorption model of the gas/aerosol partitioning of organic compounds in the atmosphere, Atmos. Environ., 28(2), 185-188, 1994.

Perri, M. J., Lim, Y. B., Seitzinger, S. P., and Turpin, B. J.: Organosulfates from glycolaldehyde in aqueous aerosols and clouds: laboratory studies, Atmos. Environ., 44(21-22), 26582664, 2010.

Petters, M. D. and Kreidenweis, S. M.: A single parameter representation of hygroscopic growth and cloud condensation nucleus activity, Atmos. Chem. Phys., 7, 1961-1971, doi:10.5194/acp-71961-2007, 2007.

Pun, B. K. and Seigneur, C.: Investigative modeling of new pathways for secondary organic aerosol formation, Atmos. Chem. Phys., 7, 2199-2216, doi:10.5194/acp-7-2199-2007, 2007.

Ruiz-Montoya, M., and Rodriguez-Mellado, J. M.: Use of convolutive potential sweep voltammetry in the calculation of hydration equilibrium constants of $\alpha$-dicarbonyl compounds, J. Electroanal. Chem., 370, 183-187, 1994.

Ruiz-Montoya, M. and Rodriguez-Mellado, J. M.: Hydration constants of carbonyl and dicarbonyl compounds comparison between electrochemcial and no electrochemcial techniques, Portugaliae Electrochim. Acta, 13, 299-303, 1995.

Russell, L. M.: Aerosol organic-mass-to-organic-carbon ratio mea- 
surements, Environ. Sci. Technol., 37, 2982-2987, 2003.

Sander, R.: Compilation of Henry's law constants for inorganic and organic species of potential importance in environmental chemistry (Version 3), http://www.henrys-law.org (last access: April 2010), 1999.

Sander, S. P., Friedl, R. R., Golden, D. M., Kurylo, M. J., Moortgat, G. K., Keller-Rudek, H., Wine, P. H., Ravishankara, A. R., Kolb, C. E., Molina, M. J., Finlayson-Pitts, B. J., Huie, R. E., and Orkin, V. L.: Chemical Kinetics and Photochemical Data for Use in Atmospheric Studies, Evaluation Number 15, JPL Publication 06-02, Jet Propulsion Laboratory, Pasadena, CA, USA, 2006.

Schuchmann, M. N., Zegota, H., and von Sonntag, C.: Acetate peroxyl radicals $\mathrm{O}_{2} \mathrm{CH}_{2} \mathrm{CO}_{2}^{-}$: A study on the radiolysis and pulse radiolysis of acetate in oxygenated aqueous solutions, $Z$. Naturforschung, 40B, 215-221, 1985.

Schwartz, S.: Mass transport considerations pertinent to aqueous phase reactions of gases in liquid water clouds, in: chemistry of Multiphase Atmospheric Systems, edited by: Jaeschke, W., NATO ASI Series, Springer, Berlin, 415-471, 1986.

Schweitzer, F., Magi, L., Mirabel, P., and George, C.: Uptake rate constants of methanesulfonic acid and glyoxal by aqueous droplets, J. Phys. Chem. A, 102, 593-600, 1998.

Seinfeld, J. H. and Pandis, S. N.: Atmospheric chemistry and physics, John Wiley \& Sons, New York, 1326 pp., 1998.

Seinfeld, J. H. and Pankow, J. F.: Organic Atmospheric Particulate Matter, Ann. Rev. Phys. Chem., 54, 121-140, 2003.

Shapiro, E. L., Szprengiel, J., Sareen, N., Jen, C. N., Giordano, M. R., and McNeill, V. F.: Light-absorbing secondary organic material formed by glyoxal in aqueous aerosol mimics, Atmos. Chem. Phys., 9, 2289-2300, doi:10.5194/acp-9-2289-2009, 2009.

Sinreich, R., Coburn, S., Dix, B., and Volkamer, R.: Ship-based detection of glyoxal over the remote tropical Pacific Ocean, Atmos. Chem. Phys. Discuss., 10, 15075-15107, doi:10.5194/acpd-1015075-2010, 2010.

Solomon, S., Qin, D., Manning, M., Chen, Z., Marquis, M., Averyt, K. B., Tignor, M., and Miller, H. L.: Climate Change 2007 - The Physical Science Basis, Contribution of Working Group I to the Fourth Assessment Report of the IPCC, Intergovernmental Panel on Climate Change, Cambridge, United Kingdom and New York, NY, USA, 2007.

Sorooshian, A., Brechtel, F. J., Ervens, B., Feingold, G., Varutbangkul, V., Bahreini, R., Murphy, S., Holloway, J. S., Atlas, E. L., Anlauf, K., Buzorius, G., Jonsson, H., Flagan, R. C., and Seinfeld, J. H.: Oxalic acid in clear and cloudy atmospheres: analysis of data from International Consortium for Atmospheric Research on Transport and Transformation 2004, J. Geophys. Res., 111(D23), D13201, doi:10.1029/2005JD006880, 2006.

Sorooshian, A., Murphy, S. M., Hersey, S., Gates, H., Padro, L. T., Nenes, A., Brechtel, F. J., Jonsson, H., Flagan, R. C., and Seinfeld, J. H.: Comprehensive airborne characterization of aerosol from a major bovine source, Atmos. Chem. Phys., 8, 5489-5520, doi:10.5194/acp-8-5489-2008, 2008.

Stavrakou, T., Mller, J.-F., De Smedt, I., Van Roozendael, M., Kanakidou, M., Vrekoussis, M., Wittrock, F., Richter, A., and Burrows, J. P.: The continental source of glyoxal estimated by the synergistic use of spaceborne measurements and inverse modelling, Atmos. Chem. Phys., 9, 8431-8446, doi:10.5194/acp-9-8431-2009, 2009.

Surratt, J. D., Kroll, J. H., Kleindienst, T. E., Edney, E. O., Claeys,
M., Sorooshian, A., Ng, N. L., Offenberg, J. H., Lewandowski, M., Jaoui, M., Flagan, R. C., and Seinfeld, J. H.: Evidence for organosulfates in secondary organic aerosol, Environ. Sci. Technol., 41, 517-527, 2007.

Tan, Y., Perri, M. J., Seitzinger, S. P., and Turpin, B. J.: Effects of precursor concentration and acidic sulfate in aqueous glyoxal$\mathrm{OH}$ radical oxidation and implications for secondary organic aerosol, Environ. Sci. Technol., 43, 8105-8112, 2009.

van Pinxteren, D., Plewka, A., Hofmann, D., Müller, K., Kramberger, H., Svrinca, B., Bächmann, K., Jaeschke, W., Mertes, S., J. L. Collett, and Herrmann, H.: Schmücke hill cap cloud and valley stations aerosol characterisation during FEBUKO (II): organic compounds, Atmos. Environ., 39, 4305-4320, 2005.

Volkamer, R., Molina, L. T., and Molina, M. J.: DOAS measurement of glyoxal as an indicator for fast VOC chemistry in urban air, Geophys. Res. Lett., 32, L08806, doi:101029/102005GL022616, 2005.

Volkamer, R., Jimenez, J. L., SanMartini, F., Dzepina, K., Zhang, Q., Salcedo, D., Molina, L. T., Worsnop, D. R., and Molina, M. J.: Secondary organic aerosol formation from anthropogenic air pollution: rapid and higher than expected, Geophys. Res. Lett., 33, L17811, doi:10.1029/2006GL026899, 2006.

Volkamer, R., SanMartini, F., Molina, L. T., Salcedo, D., Jimenez, J., and Molina, M. J.: A missing sink for gas-phase glyoxal in Mexiko City: formation of secondary organic aerosol, Geophys. Res. Lett., 34, L19807, doi:10.1029/2007GL030752, 2007.

Volkamer, R., Ziemann, P. J., and Molina, M. J.: Secondary Organic Aerosol Formation from Acetylene $\left(\mathrm{C}_{2} \mathrm{H}_{2}\right)$ : seed effect on SOA yields due to organic photochemistry in the aerosol aqueous phase, Atmos. Chem. Phys., 9, 1907-1928, doi:10.5194/acp9-1907-2009, 2009.

Volkamer, R., Coburn, S. C., Dix, B. K., and Sinreich, R.: The Eastern Pacific Ocean is a source for short lived atmospheric gases: glyoxal and iodine oxide, CLIVAR Exchanges, 15(2), 30-33, 2010a.

Volkamer, R., Sheehy, P., Molina, L. T., and Molina, M. J.: Oxidative capacity of the Mexico City atmosphere - Part 1: A radical source perspective, Atmos. Chem. Phys., 10, 6969-6991, doi:10.5194/acp-10-6969-2010, 2010b.

von Sonntag, C. and Schuchmann, H.-P.: Aufklärung von Peroxylradikalreaktionen in wäßriger Lösung mit strahlenchemischen Techniken, Angew. Chem., 103, 1255-1279, 1991.

Wang, L., Khalizov, A. F., Zheng, J., Xu, W., Ma, Y., Lal, V., and Zhang, R.: Atmospheric nanoparticles formed from heterogeneous reactions of organics, Nat. Geosci., 3, 238-242, 2010.

Warneck, P.: In-cloud chemistry opens pathway to the formation of oxalic acid in the marine atmosphere, Atmos. Environ., 37, 2423-2427, 2003.

Wasa, T. and Musha, S.: Polarographic behavior of glyoxal and its related compounds, Bull. Univ. Osaka Prefect. Set. A, 19, 169$180,1970$.

Weinstein-Lloyd, J. and Schwartz, S. E.: Low-intensity radiolysis study of free-radical reactions in cloudwater: $\mathrm{H}_{2} \mathrm{O}_{2}$ production and destruction, Environ. Sci. Technol., 25, 791-800, 1991.

Zhou, X. and Mopper, K.: Apparent partition coefficients of 15 carbonyl compounds between air and seawater and between air and freshwater; implications for air-sea exchange, Environ. Sci. Technol., 24(12), 1864-1869, 1990. 